OPEN ACCESS

Edited by:

Sami Souissi,

Lille University of Science and Technology, France

Reviewed by:

Khor Waiho,

University of Malaysia Terengganu,

Malaysia

Yun-Zhang Sun,

Jimei University, China

*Correspondence.

Miquel Planas

mplanas@iim.csic.es

Specialty section:

This article was submitted to

Marine Fisheries, Aquaculture

and Living Resources,

a section of the journal

Frontiers in Marine Science

Received: 09 June 2020

Accepted: 13 July 2020

Published: 31 July 2020

Citation:

Planas M, Olivotto I, González MJ, Laurà $R$ and Zarantoniello M (2020) A

Multidisciplinary Experimental Study on the Effects of Breeders Diet on

Newborn Seahorses (Hippocampus guttulatus). Front. Mar. Sci. 7:638.

doi: 10.3389/fmars.2020.00638

\section{A Multidisciplinary Experimental Study on the Effects of Breeders Diet on Newborn Seahorses (Hippocampus guttulatus)}

\author{
Miquel Planas ${ }^{1 *}$, Ike Olivotto ${ }^{2}$, María Jesús González ${ }^{3}$, Rosaria Laurà ${ }^{4}$ and \\ Matteo Zarantoniello² \\ ${ }^{1}$ Department of Ecology and Marine Resources, Instituto de Investigaciones Marinas (CSIC), Vigo, Spain, ${ }^{2}$ Dipartimento di \\ Scienze della Vita e dell'Ambiente, Università Politecnica delle Marche, Ancona, Italy, ${ }^{3}$ Marine Products Chemistry, Instituto \\ de Investigaciones Marinas (CSIC), Vigo, Spain, ${ }^{4}$ Dipartimento di Scienze Veterinarie, Università di Messina, Messina, Italy
}

The global trade in seahorses is increasing and new rearing techniques are currently available for a few species. One of the main bottlenecks in seahorse production is reproductive success, which is dependent upon the administration of high quality diets to breeders. However, little is known about the most adequate diets, on how they should be administered and on how they might affect newborn performance. In this study, three homogeneous groups of adult seahorses Hippocampus guttulatus were maintained in captivity. Each group was fed on one of the following diets since the onset of the breeding period: unenriched adult Artemia (diet A), unenriched adult Artemia and mysidaceans (diet $\mathrm{AM}$ ) and mysidaceans (diet M). As a positive control, a wild pregnant male was used. The mixed diet AM provided the highest overall breeding success and reasonable fatty acid profiles, and better resembled newborn from a wild male. The use of mysidaceans solely (Diet M) provided the worse results in spite of the high DHA content. Significant differences were observed in newborn characteristics and fatty acid profiles among dietary groups and along the breeding season, especially in total n-3 HUFA and DHA. Monospecific diets including Artemia or mysidaceans very likely suffered nutritional deficiencies, which were reflected in morphological alterations of the muscle tissue (diet A) or abnormal early mortalities in newborn (diet M). Three progressive stages were identified along the whole breeding period: initial mixed capitalincome period (100-120 days since the onset of the breeding period), followed by an inflection period (short transitional stage - income sources), and finally a long period characterized by the use of income sources and the progressive exhaustion of body reserves. Special attention should be deserved to the progressive changes in fatty acid profiles along the breeding season, resulting in a decrease in newborn performance. Considering the time required for a diet to be reflected in newborn, we recommend Hippocampus guttulatus breeders to be fed on a high quality diet for at least 3 months prior the breeding period.

\footnotetext{
Keywords: syngnathidae, seahorse, Hippocampus, diet, breeding, newborn, quality
} 


\section{INTRODUCTION}

The global trade in seahorses is estimated to exceed 20 million animals per year to sustain the aquarium trade, the traditional Chinese medicine and as souvenirs (Vincent, 1996; Planas et al., 2017a). In addition, because of the destruction and degradation of their coastal habitats (seagrasses, coral reefs, and mangroves), wild populations are progressively declining (Vincent, 1996; Martin-Smith et al., 2004). At present, many are the concerns over their long-term viability in nature (Vincent, 1996; Vincent et al., 2011; Kumaravel et al., 2012) and all seahorses species are included in Appendix II list of endangered species by CITES (Convention for the International Trade in Endangered Species).

Aquaculture represents a valid alternative to wild captured seahorses but ex-situ production still needs to face several biological and technical challenges (Cohen et al., 2016; Planas et al., 2017a). Both, low spawning quality and juvenile survival rates are the most critical factors for optimizing commercial seahorse aquaculture (Adams et al., 2001; Chang and Southgate, 2001; Lin et al., 2007).

Reproduction represents a key aspect in breeding success, and broodstock feeding/nutrition is doubtless, one of the key factors to sustain reproduction in teleost (Migaud et al., 2013). The dietary effect on the output performance (egg and fry quality and quantity) is well known in fishes, and many studies have reported the importance of lipids and fatty acids (FAs) (Rainuzzo, 1993; Bromage, 1995; Izquierdo et al., 2001; Sargent et al., 2002; Tocher, 2003, 2010; Pavlov et al., 2004). Broodstock preparation is thus a critical step in the success of the spawning process of a certain species. On this regard, many studies have been directed toward egg quality in oviparous fishes and the underlying characteristics to produce viable fry (Kiørsvik et al., 1990; Brooks et al., 1997). The egg's potential to produce viable fry is determined by several physical, genetic, and chemical factors, including the initial physiological processes occurring in the egg itself (Kjørsvik et al., 1990).

The ongoing process of oocytes maturation is one of the most metabolic demanding activities in fish and the quality of parental nutrition is thus of primary importance for the appropriate allocation of macromolecules into the oocytes and their maturation (Izquierdo et al., 2001; Volkoff and London, 2018). However, there is a scarcity of studies focused on breeding performance and egg or fry quality in fishes with male pregnancy such as syngnathids (pipefish and seahorses). Due to the uncommon nature of reproduction, syngnathids offer a unique opportunity to examine pathways of repercussion of breeder's dietary resources on breeding performance and the resulting newborn quality. Reproduction in seahorses has received increasing attention in recent years, mostly on the effect of environment (e.g., photoperiod regime and temperature) (Lin et al., 2006, 2008b; Planas et al., 2010, 2013) zootechnical conditions (e.g., sex ratio, aquaria design, and seahorse size) (Woods, 2000; Dzyuba et al., 2006; Faleiro et al., 2008, 2016; Planas et al., 2008) and biological / physiological features (Boisseau, 1967; Carcupino et al., 2002; Poortenaar et al., 2004; Stölting and Wilson, 2007; Scobell and MacKenzie, 2011; Zhang et al., 2019; Wittington and Friesen, 2020). Only a few studies have focused on the effects of feeding and dietary sources on breeding success and newborn features in seahorses under ex-situ conditions (Lin et al., 2007; Faleiro and Narciso, 2010; Binh and Serrano, 2012; Otero-Ferrer et al., 2012, 2016, 2020; Palma et al., 2012, 2017; Saavedra et al., 2015).

Seahorses (Hippocampus spp.) are batch spawners with cyclical egg maturation and repeated mates within the breeding season. The eggs produced by females are transferred to the brood pouch of males, where embryogenesis will take place for 2-4 weeks, depending on the species and temperature (Foster and Vincent, 2004). The sealed brood pouch of the male works as a pseudo-placenta, not only providing protection and oxygen to the developing embryos, but also nutrients (Wilson et al., 2001; Carcupino et al., 2002; Stölting and Wilson, 2007). As a consequence both female and male nutrition play a role on the embryonic and fry quality and development, but unfortunately, this topic remains one of the less studied subjects in seahorses (Olivotto et al., 2011b; Cohen et al., 2016).

The European long-snouted seahorse Hippocampus guttulatus Cuvier has been identified as a potential candidate for the marine ornamental trade (Cohen et al., 2016). Rearing techniques are currently available for this species but the breeding success (especially mating events) are still not optimized (Olivotto et al., 2011b; Planas et al., 2017a). Male competition is rather frequent resulting in mating interruption, and juvenile number and size decrease over the time in captive conditions (Faleiro et al., 2008). A bottleneck in breeding performance relies on both type and nutritional quality of diets. In captivity, both frozen and alive feed are usually used to nourish the broodstock, including mysid shrimps, amphipods and Artemia brine shrimps (Woods and Valentino, 2003; Olivotto et al., 2008; Palma et al., 2008; Murugan et al., 2009; Planas et al., 2017a). As concerns mysid shrimps, they are generally considered an optimal diet for seahorses (Woods and Valentino, 2003; Otero-Ferrer et al., 2012). Nutritionally enriched Artemia has received great attention and is presently widely employed (Woods, 2001; Wong and Benzie, 2003; Woods and Valentino, 2003; Planas et al., 2008) especially because it is easily cultured up to the adult stage, provides satisfactory n-3 HUFA and docosahexaenoic acid (DHA) contents after a long-time enrichment (Planas et al., 2017b) and supports high growth rates in $H$. guttulatus (Planas et al., 2008). However, it has been reported that the breeding performance in H. hippocampus decreased when fed on Artemia compared to diets including mysidaceans (Otero-Ferrer et al., 2012).

In the present study, the following questions have been addressed: (1) how experimental diets are assimilated (stable isotope analysis) by breeders and reflected in general features and biochemical composition of $H$. guttulatus newborn? (2) do mixed diets perform better than monospecific ones? and (3) Does $H$. guttulatus follow a mixed income-capital breeding strategy? The main objectives of the study were (1) to propose a breeder's diet enhancing reproduction performance in the selected species, and (2) to ascertain when and how long the diet should be administered to provide its beneficial effect. To our knowledge, this is the first multiapproach study on the effect of breeder's diet on reproductive performance and newborn quality in H. guttulatus. 


\section{MATERIALS AND METHODS}

\section{Microalgae and Live Prey}

Microalgae (Phaeodactylum tricornutum, Rhodomonas lens, and Isochrysis galbana) were cultured at $22 \pm 1^{\circ} \mathrm{C}$ in $80 \mathrm{~L}$ plastic bags containing sterilized seawater supplemented with F2P (100 $\mathrm{g} \mathrm{L}^{-1}$ ) media (VarAqua). Additionally, silicates were added to $P$. tricornutum cultures, and $200 \mu \mathrm{L}$ F2P media to the R. lens culture flasks.

Artemia cysts (AF, Inve, Spain) were hatched at $28^{\circ} \mathrm{C}$ for $20 \mathrm{~h}$ in $20 \mathrm{~L}$ units, and the freshly hatched nauplii $(614 \pm 140 \mu \mathrm{m}$ in length) gently rinsed with tapwater, collected on a $125 \mu \mathrm{m}$ mesh, rinsed, and offered to seahorse juveniles.

Adult non-enriched Artemia was produced to feed adult seahorses during the breeding period. For that, the nauplii were hatched from MC450 cysts (Ocean Nutrition, Spain) and grown in $100 \mathrm{~L}$ units, at $26-28^{\circ} \mathrm{C}$ with gentle aeration and constant light. Adult Artemia was long-time enriched (3-6 days) to feed breeders prior to the start of the experiment but not during the experimental period. The enrichment was carried out in Artemia from day 16 onward on a mixture consisting on live microalgae $P$. tricornutum and I. galbana $\left(10^{7}\right.$ cells $\left.\mathrm{mL}^{-1}\right)$, red pepper $\left(0.015 \mathrm{~g} \mathrm{~L}^{-1}\right)$, and dried Spirulina $\left(0.03 \mathrm{~g} \mathrm{~L}^{-1}\right)$ (Planas et al., 2017a).

Copepods (Acartia tonsa; $614 \pm 140 \mu \mathrm{m}$ in length) were cultivated for the early feeding of seahorse juveniles in $700 \mathrm{~L}$ tanks at $26-27^{\circ} \mathrm{C}$ and 38 salinity, at an initial density of 1 copepod $\mathrm{mL}^{-1}$. Copepods were fed every two days on the microalgae $R$. lens $\left(10^{3}\right.$ cells $\left.\mathrm{mL}^{-1}\right)$. Siphoning of the culture tanks and water renewals (10\% of the total volume) were carried out three times per week.

\section{Seahorse Breeding and Rearing}

Animal capture, handling and sampling were conducted in compliance with all bioethics standards on animal experimentation of the Spanish Government (Real Decreto 1201/2005, 10th October 2005) and the Regional Government Xunta de Galicia (REGA ES360570202001/15/FUN/BIOL.AN/MPO01).

The adults of $H$. guttulatus seahorses used in the present study were reared in captivity or collected in Galicia (NW Spain) from August 2016 to January 2017 with permission of the Regional Government Xunta de Galicia. Prior to the start of the experiment, seahorses were maintained at the facilities of Instituto de Investigaciones Marinas (CSIC) in Vigo (Spain) in $320 \mathrm{~L}$ aquaria in a semi-closed system with a $10-14 \%$ daily renewal of seawater (Planas et al., 2008) and submitted to temperature and photoperiod natural-like regimes (Planas et al., 2010,2013 ) fluctuating from $15^{\circ} \mathrm{C}$ (Winter) to $19^{\circ} \mathrm{C}$ (Summer) and from 10L:14D (Winter) to 16L:8D (Summer), respectively. Water quality was checked periodically for $\mathrm{NO}_{2}, \mathrm{NO}_{3}$, and $\mathrm{NH}_{4} / \mathrm{NH}_{3}$ content $\left(0 \mathrm{mg} \mathrm{L}^{-1}\right)$. Salinity and $\mathrm{pH}$ levels were $37 \pm 2$ and $8.0 \pm 0.2$, respectively, for both species. Wastes and uneaten food were removed daily by siphoning the bottom of aquaria.

Males and females were maintained separate until the start of the experiment in mid-March 2017, when all seahorses were randomly distributed (1:1 sex ratio; six pairs per aquaria) in three $320 \mathrm{~L}$ aquaria and maintained for a whole breeding season (until early October 2017). All aquaria were maintained under the same conditions except for the diet administered. Temperature and photoperiod regimes were as described above. The average size (curved standard length) and weight of seahorse breeders ( $17.4 \pm 2.6 \mathrm{~cm}$ and $11.50 \pm 5.0 \mathrm{~g}$, respectively) did not differ across experimental groups (ANOVA, $p=0.702$, $17.4 \pm 2.6 \mathrm{~cm}$; ANOVA, $p=0.470,11.5 \pm 5.0 \mathrm{~g})$. Seahorse broodstocks were continuously monitored to check for newborn release from male's pouch.

Prior to the breeding period, all breeders were fed for 25 months on a diet based on enriched adult Artemia and captured/frozen mysidaceans (Siriella armata and Leptomysis sp.). The length of the prey was 5-7 $\mathrm{mm}$ for Artemia and about $1-1.5 \mathrm{~cm}$ for mysidaceans. During the breeding period, each husbandry aquaria received two daily doses (ad libitum) of different diets (Figure 1):

- Diet A: Cultivated adult non-enriched Artemia.

- Diet M: Captured (Siriella armata and Leptomysis sp.) and frozen (Neomysis sp.; Ocean Nutrition, United States) mysidaceans (1:1).

- Diet AM: Mixture (1:1) of diets A and M.

Small portions of the breeders dorsal fin (partial fin-clipping; about $20 \mathrm{~m}^{2}$ surface) were sampled at the onset and at the end of the breeding period, and properly stored for further stable isotopic analysis (SIA) (Valladares and Planas, 2012).

Newly released juveniles were carefully collected by siphoning, counted and transferred (2-5 juveniles $\left.\mathrm{L}^{-1}\right)$ to $30 \mathrm{~L}$ pseudokreisel aquaria connected to a semi-opened recirculation system (Blanco et al., 2014). Each batch was cultivated in duplicate (whenever possible) until day 7 after male's pouch release (DAR) at $19^{\circ} \mathrm{C}$ under a constant $14 \mathrm{~L}: 10 \mathrm{D}$ photoperiod. The aquaria were filled with seawater filtered by a series of filter-cartridges $(20,10,5$, and $1 \mu \mathrm{m})$ and $\mathrm{UV}$ treated $\left(76 \mathrm{w} ; 16 \mathrm{~L} \mathrm{~min}^{-1}\right.$ ) (JR1/50). The rearing system included a degasifying column and two $50 \mathrm{~L}$ chambers including mechanical (up to $20 \mu \mathrm{m}$ ) and biological filters (perforated plastic bio-balls) and aerators. From the biofilter unit, the seawater was pumped to $36 \mathrm{w} \mathrm{UV}$ units (AquaMedic ${ }^{\circledR}$, Germany) and then to a $50 \mathrm{~L}$ reservoir aquarium, being finally routed by gravity toward the rearing aquaria (Planas et al., 2012).

Newborn seahorses were fed according to the following optimized schedule (Blanco and Planas, 2015):

- 0-5 DAR: Two daily doses of Acartia tonsa (0.67 copepods $\mathrm{mL}^{-1}$ dose $\left.^{-1}\right)$.

- 6-7 DAR: One daily dose of Acartia tonsa (0.67 copepods $\mathrm{mL}^{-1}$ dose $^{-1}$ ) and one daily dose of Artemia nauplii (1 Artemia $\mathrm{mL}^{-1}$ dose $^{-1}$ ).

Dead seahorses were removed (8:00 am and 15:00 pm) and counted daily. Final survivals of juveniles were recorded at 7 DAR $\left(\mathrm{M}_{50}\right.$ at $18-21^{\circ} \mathrm{C}$ occurs at 6.3-6.7 DAR) (Planas et al., 2012).

For each experimental group, samples of newborn juveniles (see further sections for details) were randomly collected before 


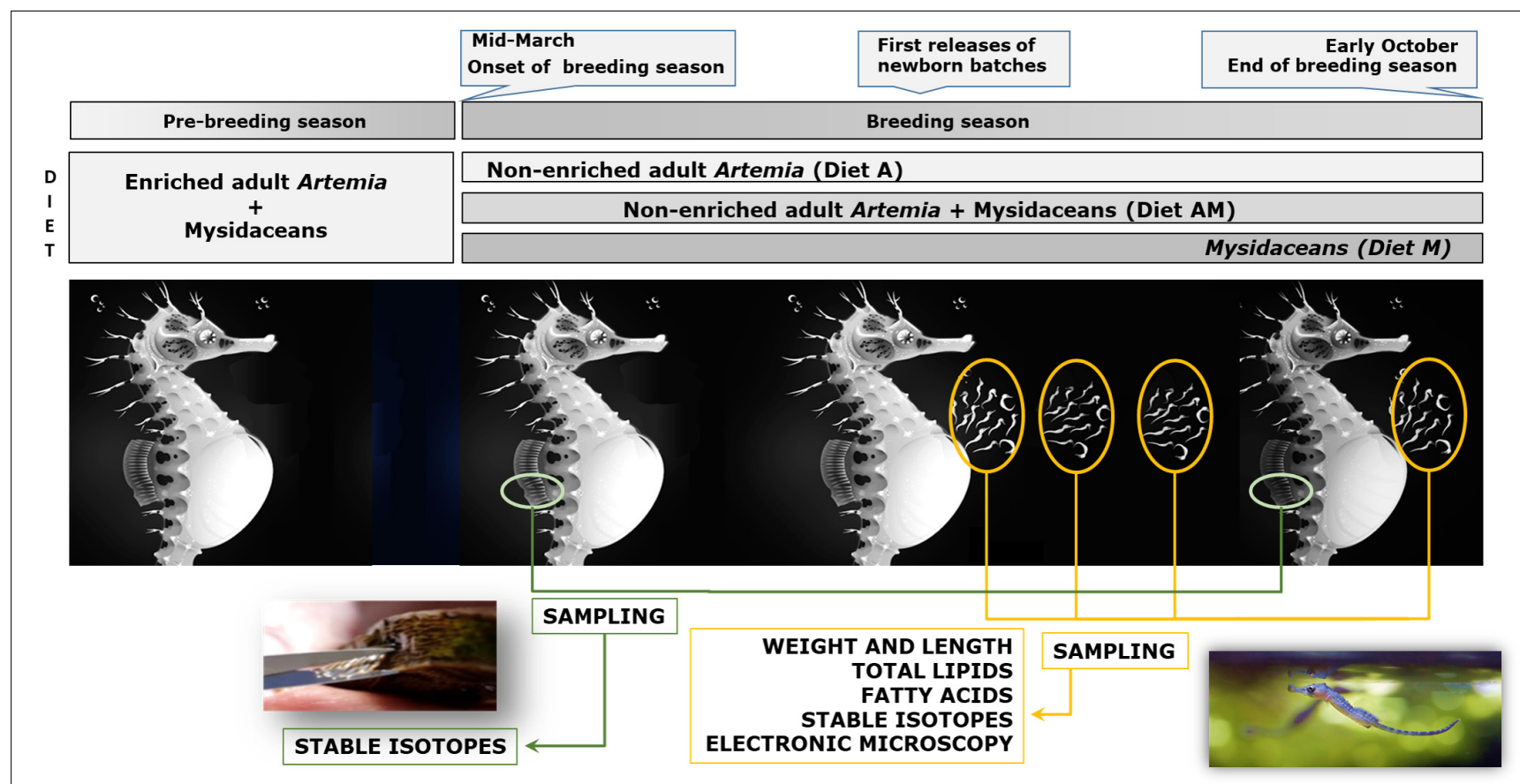

FIGURE 1 | General scheme of the experimental framework (breeders fed on diets A, AM, and M) and sampling (dorsal fin and newborn). Seahorse illustration by Sergio Picazo Ferro (https://sergiopicazo.com/).

first feeding, euthanized with Tricaine MS-222 (0.1 $\mathrm{mg} \mathrm{L}^{-1}$, Sigma Aldrich), rinsed with distilled water, and conserved at $80^{\circ} \mathrm{C}$ for further FAs and isotopic analyses.

For length and weight measurements, sampled seahorses $(n=15)$ were transferred to Petri dishes, photographed and weighed (pooled individuals) on a Sartorius microbalance MC210P ( $\pm 0.01 \mathrm{mg})$. Curved standard lengths $(\mathrm{SL}=$ head + trunk + curved tail $)$ were measured from digital photographs using an image processing software (NIS Elements, Nikon).

\section{Sample Analysis}

Total lipids from live prey and juveniles (pools of 10$20 \mathrm{mg}$ dry weight per sample) (i.e., 25-40 newborn) were extracted according to Bligh and Dyer (1959). Aliquots of total lipid extracts with known lipid content were centrifuged, resuspended with $0.5 \mathrm{M}$ ammonium formate solution, freezedried and stored at $-80^{\circ} \mathrm{C}$ until further FAs analyses. Total lipid content was quantified gravimetrically (Herbes and Allen, 1983). FA composition of lipids was analyzed by gaschromatography (GC) according to Christie (1982). Lipids were transmethylated (Lepage and Roy, 1986) and Fas analyzed by GC (Perkin Elmer, Clarus 500 gas chromatograph) as described in Planas et al. (2010). Samples were analyzed in duplicate.

Carbon $\left(\delta^{13} \mathrm{C}\right)$ and nitrogen $\left(\delta^{15} \mathrm{~N}\right)$ isotope signatures and elemental composition (total $\mathrm{C}$ and $\mathrm{N}$ ) were analyzed in both prey and seahorse samples (fin of breeders and bulk juveniles). Frozen juveniles ( $n>5$; pooled individuals) were dried for $48 \mathrm{~h}$ $\left(60^{\circ} \mathrm{C}\right)$, weighted and manually homogenized. The analyses were performed on sub-samples of $0.2-1.0 \mathrm{mg}$ dry weight biomass at Servizos de Apoio á Investigación (SAI) of the University of A Coruña (Spain) as reported by Valladares et al. (2016). As defatting of samples prior to isotopic analysis is recommended when lipid content exceeds 5\% weight (C:N > 3.56) (Post, 2002) samples were not defatted but arithmetical corrected factors (Supplementary Table 1) were applied considering defatting (copepods, Artemia nauplii and metanauplii, and seahorse fins or juveniles) or defatting + acidification $(10 \% \mathrm{HCl})$ (Mysidacea and adult Artemia). The samples were measured by continuous flow isotope ratio mass spectrometry using a FlashEA1112 elemental analyzer (Thermo Finnigan, Italy) coupled to a Delta Plus mass spectrometer (FinniganMat, Bremen, Germany) through a Conflo II interface. Stable isotope abundances are expressed as permil $(\% 0)$ in conventional delta relative to VPDB (Vienna Pee Dee Belemnite) and Atmospheric Air. The precision (standard deviation) for the analysis of $\delta^{13} \mathrm{C}$ and $\delta^{15} \mathrm{~N}$ of the laboratory standard (acetanilide) was $\pm 0.15 \%$ ( 1 -sigma, $n=10)$. Standards were run every 10 biological samples.

Transmission electron microscopy (TEM) was applied to abdominal portions of seahorses (three newborns per dietary treatment). The samples were processed for Durcupan ACM (Fluka) resin embedding as follows: pieces fixed in $2.5 \%$ glutaraldehyde in $0.2 \mathrm{M}$ phosphate-buffered saline ( $\mathrm{pH} 7.4$ ), for $2 \mathrm{~h}$ at $4^{\circ} \mathrm{C}$, were washed repeatedly in the same buffer and postfixed in $1 \%$ osmium tetroxide in $0.2 \mathrm{M}$ phosphate-buffered saline for $1 \mathrm{~h}$ at $4^{\circ} \mathrm{C}$. Then, the tissues were dehydrated with increasing alcohol concentrations. The dehydrated pieces were embedded in Durcupan ACM (Squadrito et al., 2017). Finally, the sections were obtained with a Reichert Jung Ultracut E. 
Semi-thin sections $(1 \mu \mathrm{m})$ were stained with toluidine blue and examined with a light microscope. Ultrathin sections (740 ̊) were obtained from selected areas of the semi-thin sections, stained with uranyl acetate and lead citrate, and examined and photographed with a transmission electron microscope (JEOL JEM 1400 Flash) (Viña et al., 2014).

\section{Data Analysis}

All statistical analyses were conducted in $\mathrm{R}$ v.3.6.1 ( $\mathrm{R}$ Core Team, 2014). Variability across treatments was examined by ANOVA or non-parametric Kruskal-Wallis test for independent samples, depending on significant deviations from normality and homogeneity of variance, as examined by the ShapiroWilks and Levene tests, respectively (ggpubr v0.2.5 R package) (Kassambara, 2020a). When significant, A Kruskal-Wallis test followed by Wilcoxon range comparisons were applied (Pgirmess v1.6.9 package of R) (Giraudoux et al., 2018). Significance levels were set at $p<0.05$.

The Jonckheere-Terpstra trend test (J-T test) was applied to individual FA data for an ordered alternative hypothesis within an independent sample (between-seahorse groups) design (clinfun v1.0.15 package in R) (Venkatraman, 2018). The test has more statistical power than the Kruskal-Wallis test, incorporating information about whether the order of the groups is meaningful (Siegel and Castellan, 1988). Hence, we applied the test to check whether the more proportions of mysidaceans in the diet (order: A - AM - M), the more the independent variable tested will go down or up.

Correlations between variables in the whole dataset and the resulting network plots of variables were explored with ggraph v2.0.2 (Pedersen, 2020) and corrr v0.4.2 (Kuhn et al., 2020) R packages. Hierarchical clustering of both variables and newborn batches was performed with Ward's method (provided the highest agglomerative coefficients) using factoextra v1.0.7 (Kassambara, 2020b) and ComplexHeatmap v3.11 (Gu et al., 2016) packages in R. Additionally, principal component analyses (PCA) were performed to summarize and visualize the information of the datasets. For that, we used factoMineR v2.3 (Husson et al., 2020), factoextra v1.0.7 (Kassambara, 2020b), and corrplot v0.8.4 (Wei et al., 2017) packages in $\mathrm{R}$. The data values were standardized (mean $=0$; sd $=1)$ for clustering and PCA.

Graphics were constructed using ggplot2 v3.3.0 (Wickham et al., 2020) and lattice v0.20-41 (Sarkar et al., 2020) packages in R.

\section{RESULTS}

\section{Diet Assimilation}

The protein content in breeder's diets increased from diets A to $\mathrm{M}$, whereas lipid content decreased due to the lower lipid content in mysidaceans compared to adult Artemia (\% $\mathrm{C}$ and $\mathrm{C} / \mathrm{N}$ in Table 1). Prey (and diets) offered to seahorse breeders also differed notably in FA profiles (Table 2 and Supplementary Figure 1). Compared to mysidaceans, adult nonenriched Artemia was richer in saturated FA (35.3\%) (16:0, 17:0, and 18:0), n-6 FA (18:2n-6c and 18:3n-6c) (21.5\%), and n-7 FA (18:1n-7) (18.8\%). Captured and frozen mysidaceans were remarkably richer than Artemia in n-3 HUFA (42.6-45.2\%, respectively) (EPA and especially DHA) and showed much higher DHA/EPA, DHA/ARA, and n-3/n- 6 ratios.

The incorporation of the experimental diets in breeder tissues was analyzed considering dietary isotopic profiles (Table 1) and the resulting isotopic changes in dorsal fins (initial vs final) (Table 2). Differences in isotopic signatures of diets corresponded approximately to one trophic level, with values ranging from -22.12 to $-20.53 \%$ for $\delta^{13} \mathrm{C}(\Delta=1.59)$ and from 7.67 to $10.83 \%$ in $\delta^{15} \mathrm{~N}(\Delta=3.16)$.

Initial isotope values for $\delta^{13} \mathrm{C}$ and $\delta^{15} \mathrm{~N}$ in dorsal fin at the onset of the experimental breeding period did not differ significantly (ANOVA, $P=0.192$ and 0.143 , respectively) (Table 2). At the end of the experiment, changes in signatures for both isotopes in fins were inversely correlated (linear regression, $R^{2}=0.994$ ) across treatments (Supplementary Figure 2) and strongly agreed with isotope values of the corresponding diets, with significantly lower $\delta^{15} \mathrm{~N}$ signatures in the group fed uniquely on Artemia (K-W test, $P=0.044)$. Isotopic changes $(\Delta \delta)$ in fins during the breeding season were $2.97,-0.20$, and -1.89 for $\delta^{13} \mathrm{C}$, and $-1.42,0.88$, and 2.58 for $\delta^{15} \mathrm{~N}$, respectively (Table 3 ). Isotopic changes between final isotopic values in dorsal fins and diets $\mathrm{A}, \mathrm{AM}$, and $\mathrm{M}$ were $8.13,4.14$, and 2.50 for $\delta^{13} \mathrm{C}$, and 2.62, 4.25 , and 3.91 for $\delta^{15} \mathrm{~N}$, respectively.

\section{Breeding Performance}

The total amount of newborn batches produced in treatments A, $\mathrm{AM}$, and $\mathrm{M}$ were 4, 7, and 3, respectively, and the total production of newborns were 534, 1,416, and 248, respectively (Table 4). Average batch size in treatment AM (202 \pm 82 newborns; $\max =343)$ was higher than in treatments $A(134 \pm 83)$ and $M$ $(84 \pm 72)$ but differences across treatments were not significant (ANOVA, $P=0.331$ ) due to the large standard deviations of means. Newborn production started earlier and extended over a longer period for group AM breeders (from day 72 to 210 of the breeding period). The opposite occurred in group $M$ (from days 152 to 179). In group A, newborn batches were released from day 121 to day 202 .

Newborn differed in length (K-W test, $p=0.018)$ but not in dry weight $(0.60-0.74 \mathrm{mg})(\mathrm{K}-\mathrm{W}$ test, $P=0.440)$ (Table 4 and Supplementary Figure 3). Newborns from treatment A $(12.9 \pm 0.7 \mathrm{~mm})$ were significantly smaller in length than those from treatments AM $(14.7 \pm 0.7 \mathrm{~mm})$ and $\mathrm{M}(14.1 \pm 0.2 \mathrm{~mm})$.

Survivals at 7 DAR were high but not significantly different across treatments (K-W test, $P=0.066$ ) (Table 4), ranging from $94.0 \pm 5.3 \%$ in treatment $A$ to $61.4 \pm 19.2 \%$ in treatment M. First mortalities in treatment $M$ occurred at $2 \mathrm{DAR}$, with a peak at 4-5 DAR (Figure 2). Similarly to newborn reared from a batch released by a wild male, first mortalities in treatments A and AM were delayed until 3-4 DAR.

\section{Newborn Characteristics}

Pooled samples of newborn differed in $\delta^{15} \mathrm{~N}$ across treatments (K-W test, $P=0.044$ ) but not in $\delta^{13} \mathrm{C}$, ranging from 11.21 to $14.96 \%$ and from -17.31 to $-13.86 \%$, respectively (Table 2 and Supplementary Figure 3). Mean $\delta^{15} \mathrm{~N}$ value in group A was significantly lower than those from the other groups. However, 
TABLE 1 | Average isotopic profiles $\left(\delta^{13} \mathrm{C} \%\right.$ and $\delta^{15} \mathrm{~N} \%$ ), total $\mathrm{C}$ and $\mathrm{N}$, and $\mathrm{C} / \mathrm{N}$ ratios in prey $\left(\mathrm{A}-\right.$ Artemia, $\mathrm{M}_{\mathrm{C}}-\mathrm{Captured}$ mysidaceans, and $\mathrm{M}^{\mathrm{f}}-\mathrm{Frozen}$ mysidaceans) ( $n=3$ ) and in diets for breeders (diets A, AM, and M) of Hippocampus guttulatus.

\begin{tabular}{|c|c|c|c|c|c|c|}
\hline & & $\% \mathrm{C}$ & $\% \mathbf{N}$ & $\mathrm{C} / \mathrm{N}$ & $\delta^{13} \mathbf{C} \%$ & $\delta^{15} \mathbf{N} \%$ \\
\hline \multirow[t]{3}{*}{ Prey } & Adult Artemia (A) & 43.8 & 10.3 & 4.25 & -22.12 & 7.67 \\
\hline & Captured Mysidacea $\left(\mathrm{M}^{\mathrm{C}}\right)$ & 42.3 & 12.9 & 3.92 & -24.34 & 12.71 \\
\hline & Frozen Mysidacea $\left(\mathrm{M}^{\mathrm{f}}\right)$ & 38.7 & 9.3 & 4.16 & -16.72 & 8.96 \\
\hline \multirow[t]{3}{*}{ Diet } & A & 43.8 & 10.3 & 4.25 & -22.12 & 7.67 \\
\hline & $\mathrm{AM}$ & 42.2 & 10.7 & 3.95 & -21.32 & 9.25 \\
\hline & $M\left(M_{C}+M_{f}\right)$ & 40.5 & 11.1 & 3.65 & -20.53 & 10.83 \\
\hline
\end{tabular}

See text for further details on the composition of diets. Raw isotopic data were transformed considering conversions provided in Supplementary Table 1.

mean isotopic values did not reflect the pattern of change across treatments during the breeding period. The low number of batches released in treatments $\mathrm{A}$ and $\mathrm{M}$ did not allow a precise analysis of isotopic changes but a trend could be inferred from treatment $\mathrm{AM}$, in which a progressive change in $\delta^{15} \mathrm{~N}$ toward those in the diet was noticed throughout the breeding season, with signals decreasing from 16.0 to $12.3 \%$.

Total lipids in newborn were similar in all experimental groups $(12.17-12.99 \% \mathrm{DW})(\mathrm{K}-\mathrm{W}$ test, $P=0.580)$, but significant differences were noticed for some FA in total lipids (Table 2). Significant differences across treatments $(\mathrm{K}-\mathrm{W}$ test, $P<0.05)$ were obtained for 15:0, 17:0, 18:1n-7, 20:1n-9, 20:2n-6, 20:4n6 , and 22:6n-3, total polyunsaturated FA and DHA/EPA ratio. $\mathrm{J}-\mathrm{T}$ test revealed that increasing proportions of mysidaceans in the diet of breeders promoted significant increasing trends in newborn for 14:0, 15:0, 17:0, 18:1n-9t, 20:1n-9, 20:2n-6, 20:4n6, 22:6n-3, and n-3 HUFA and DHA/EPA ratio, and declines in 16:1n-7, 18:1n-7, and 18:2n-6c (Table 2). The FA profile of newborn released by a wild male better resembled those from groups AM or M.

\section{Global Assessment}

From the correlation network developed for treatment AM (Figure 3) it can be observed that time (days elapsed from the onset of the breeding season) negatively affected survival, the relative content in saturated FA (particularly 14:0) and $\delta^{15} \mathrm{~N}$ values, but increased the content in total $\mathrm{n}-6$ FA (mainly $18: 2 n-6 c)$ and $18: 3 n-3$. Length and dry weight of newborn were positively correlated but they did not correlate with time. Size and weight were negatively correlated with $\delta^{13} \mathrm{C}$. In addition, weight was negatively and positively correlated with total monoenes and 18:0, respectively. The full results on correlation analyses are provided in Supplementary Figures 4, 5. Sample similarities were remarkably high $\left(R^{2}>0.7\right)$. However, early released newborn batches from group A were more similar to intermediate batches from group AM, and late released batches were similar, independently of the group considered. The only batch available by a wild male was similar to early batches released by males fed on diet AM.

The results obtained with PCA differed depending on the dataset used (Figure 4 and Supplementary Figure 6). PCA performed with the datasets including general newborn characteristics (Figure 4A) and FA (Figure 4B) showed the proximity of newborn from the wild male to males from groups AM and, to a lesser extent, M. The first two components of PCA accounted for 58.1 and $50.4 \%$ of total variation in the dataset. The first component PC1 clearly separated samples from group A (left side) from the others (right side). The most significantly associated variables to $\mathrm{PC} 1$ (increasing order of significance) were $\delta^{15} \mathrm{~N}$, polyunsaturated FA, DHA/AA ratio, n-3 HUFA, DHA/EPA ratio and SL for positive associations, and monounsaturated $\mathrm{FA}, \delta^{13} \mathrm{C}$ and time for negative associations (Supplementary Figures 4A,B). Main FA relevant to PC1 were 20:2n-6, 22:6n-3, $15: 0,20: 1 \mathrm{n}-9,17: 0,18: 1 \mathrm{n}-9 \mathrm{t}$, and SL (right side), and 16:1n7, 20:5n-3 and survival at 7 DAR (left side). For PC2, the most relevant proximate variables were $n-3 / n-6$, lipid content, $\mathrm{C} / \mathrm{N}$ ratio (positive association), and $\mathrm{n}-6 \mathrm{FA}$ and SL (negative association). For FA, main positive associations with PC2 were time, 20:0, 20:1n-9, 18:1n-9t, 20:3n-6, and 18:2n-6c (positive), and 24:0 and survival (negative).

Variability explained by factors PC1 and PC2 increased up to $69.8 \%$ in the PCA performed on all diets and including exclusively significant variables in K-M and J-T tests (Figure 4C). In increasing order of importance, the most significantly associated variables (Supplementary Figure 4C) to PC1were DHA, 20:2n-6, total polyunsaturated FA, total $\mathrm{N}, \delta^{15} \mathrm{~N}$, DHA/EPA ratio, 17:0, AA and 20:1n-9 for positive associations, and $18: 1 \mathrm{n}-7,16: 1 \mathrm{n}-7$ and survival for negative associations. Survival, 14:0 and saturated FA were positively associated to PC2, with negative association for time and monounsaturated 18:1n-9t and 20:1n-9.

Finally, the PCA performed for selected variables in AM dataset (other groups were not analyzed due to insufficient data) explained $69.2 \%$ of total variability with PC1 and PC2 (Figure 4D). PC1 was positively associated to DHA, 20:2n-6, total polyunsaturated FA, 15:0, $\delta^{15} \mathrm{~N}$, DHA/EPA ratio, 17:0, 20:4n6 and $20: 1 \mathrm{n}-9$, and negatively associated to $16: 1 \mathrm{n}-7,18: 1 \mathrm{n}-8$ and survival (Supplementary Figure 4D). For PC2, the mostly positive contributions were due to survival, 14:0, and total saturated FA, with time, $20: 1 n-9$ and $18: 1 n-9$ as negatively associated factors.

\section{Transmission Electron Microscopy}

Ultrathin sections of abdominal portions of newborn seahorses were observed by TEM in order to analyze the ultrastructural features of muscular tissue. Generally, TEM micrographs of skeletal muscle sections revealed a regular morphology with a normal arrangement of sarcomeres, resulting in a regularly striated appearance with a normal alternation of dark anisotrope band A (myosin and actin) and light isotrope band I (actin 
TABLE 2 | Total lipids (\% dry weight) and fatty acids (relative percentage) in prey $(n=2)$, diets and newborn seahorses.

\begin{tabular}{|c|c|c|c|c|c|c|c|c|c|c|c|}
\hline \multirow[b]{2}{*}{ Fatty acids (\%) } & \multicolumn{3}{|c|}{ Prey for seahorse breeders } & \multicolumn{3}{|c|}{ Diets for seahorse breeders } & \multicolumn{3}{|c|}{ Batches - Seahorse juveniles (0 DAR) } & \multirow[b]{2}{*}{$W(n=1)$} & \multirow[b]{2}{*}{$\mathrm{J}-\mathrm{T}$ test } \\
\hline & Adult Artemia & Frozen Mysidacea & Captured Mysidacea & Diet A & Diet AM & Diet M & $\operatorname{Diet} A(n=3)$ & Diet AM $(n=7)$ & Diet M $(n=2)$ & & \\
\hline $14: 0$ & $1.43 \pm 0.09$ & $3.41 \pm 0.02$ & $0.62 \pm 0.02$ & $1.43 \pm 0.09$ & $1.72 \pm 0.18$ & $2.02 \pm 1.97$ & $1.81 \pm 0.51$ & $1.53 \pm 0.36$ & $1.13 \pm 0.14$ & 1.35 & $\gamma^{*}$ \\
\hline 15:0 & $0.46 \pm 0.05$ & $0.84 \pm 0.03$ & $0.56 \pm 0.01$ & $0.46 \pm 0.05$ & $0.58 \pm 0.01$ & $0.70 \pm 0.20$ & $0.36 \pm 0.05^{a}$ & $0.45 \pm 0.04^{\mathrm{ab}}$ & $0.51 \pm 0.08^{b}$ & 0.53 & $\lambda^{\star}$ \\
\hline $16: 0$ & $17.92 \pm 0.92$ & $21.63 \pm 0.15$ & $21.30 \pm 0.07$ & $17.92 \pm 0.92$ & $19.69 \pm 0.22$ & $21.46 \pm 0.24$ & $17.84 \pm 1.05$ & $17.68 \pm 0.61$ & $18.07 \pm 1.00$ & 17.91 & n.s. \\
\hline $16: 1 n-7$ & $8.31 \pm 0.17$ & $9.06 \pm 0.04$ & $0.83 \pm 0.01$ & $8.31 \pm 0.17$ & $6.63 \pm 1.00$ & $4.95 \pm 5.82$ & $6.57 \pm 2.11$ & $4.02 \pm 0.90$ & $3.30 \pm 0.83$ & 2.61 & $\searrow^{* \star}$ \\
\hline $17: 0$ & $3.22 \pm 0.10$ & $1.23 \pm 0.03$ & $1.57 \pm 0.06$ & $3.22 \pm 0.10$ & $2.31 \pm 0.02$ & $1.40 \pm 0.24$ & $1.21 \pm 0.15^{a}$ & $1.41 \pm 0.08^{\mathrm{ab}}$ & $1.55 \pm 0.12^{\mathrm{b}}$ & 1.24 & $\gamma^{\star}$ \\
\hline $17: 1$ & $0.06 \pm 0.01$ & $0.12 \pm 0.09$ & $0.91 \pm 0.12$ & $0.06 \pm 0.01$ & $0.29 \pm 0.00$ & $0.51 \pm 0.56$ & $0.18 \pm 0.05$ & $0.12 \pm 0.03$ & $0.14 \pm 0.04$ & 0.13 & n.s. \\
\hline $18: 0$ & $11.44 \pm 0.56$ & $2.65 \pm 0.04$ & $4.04 \pm 0.01$ & $11.44 \pm 0.56$ & $7.39 \pm 0.55$ & $3.34 \pm 0.98$ & $13.00 \pm 0.78$ & $12.35 \pm 0.90$ & $11.24 \pm 1.97$ & 11.25 & n.s. \\
\hline $18: 1 n-7$ & $10.39 \pm 3.98$ & $4.11 \pm 0.00$ & $3.21 \pm 0.02$ & $10.39 \pm 3.98$ & $7.02 \pm 2.53$ & $3.66 \pm 0.64$ & $5.27 \pm 0.37^{b}$ & $4.42 \pm 0.37^{\mathrm{ab}}$ & $3.74 \pm 0.08^{a}$ & 5.32 & $\searrow^{* *}$ \\
\hline $18: 1 n-9 t$ & $6.97 \pm 0.50$ & $5.99 \pm 0.05$ & $8.56 \pm 0.03$ & $6.97 \pm 0.50$ & $7.12 \pm 0.91$ & $7.27 \pm 1.82$ & $9.07 \pm 0.43$ & $9.65 \pm 0.53$ & $11.01 \pm 0.75$ & 7.99 & $\nearrow^{\star \star}$ \\
\hline $18: 2 n-6 c$ & $12.55 \pm 0.68$ & $1.17 \pm 0.01$ & $1.77 \pm 0.00$ & $12.55 \pm 0.68$ & $7.01 \pm 0.29$ & $1.47 \pm 0.42$ & $3.37 \pm 1.46$ & $2.82 \pm 0.88$ & $1.42 \pm 0.17$ & 1.32 & $\searrow^{* *}$ \\
\hline $18: 3 n-3$ & $0.86 \pm 0.04$ & $1.31 \pm 0.01$ & $1.05 \pm 0.01$ & $0.86 \pm 0.04$ & $1.02 \pm 0.01$ & $1.18 \pm 0.19$ & $0.57 \pm 0.47$ & $0.40 \pm 0.28$ & $0.24 \pm 0.05$ & 0.23 & n.s. \\
\hline $18: 3 n-6 c$ & $6.36 \pm 0.36$ & $0.22 \pm 0.00$ & $0.18 \pm 0.04$ & $6.36 \pm 0.36$ & $3.28 \pm 0.01$ & $0.20 \pm 0.02$ & $0.23 \pm 0.12$ & $0.22 \pm 0.08$ & $0.16 \pm 0.04$ & 0.32 & n.s. \\
\hline $18: 4 n-3$ & $0.15 \pm 0.03$ & $0.18 \pm 0.02$ & $0.15 \pm 0.00$ & $0.15 \pm 0.03$ & $0.16 \pm 0.00$ & $0.17 \pm 0.02$ & $0.13 \pm 0.13$ & $0.22 \pm 0.15$ & $0.17 \pm 0.18$ & 0.34 & n.s. \\
\hline 20:0 & $0.64 \pm 0.01$ & $0.20 \pm 0.03$ & $0.22 \pm 0.01$ & $0.64 \pm 0.01$ & $0.43 \pm 0.00$ & $0.21 \pm 0.01$ & $0.70 \pm 0.18$ & $0.70 \pm 0.03$ & $0.78 \pm 0.10$ & 0.55 & n.s. \\
\hline 20:1n-9 & $0.30 \pm 0.01$ & $0.84 \pm 0.01$ & $0.97 \pm 0.06$ & $0.30 \pm 0.01$ & $0.60 \pm 0.00$ & $0.91 \pm 0.09$ & $0.36 \pm 0.06^{a}$ & $0.46 \pm 0.06^{\mathrm{ab}}$ & $0.57 \pm 0.07^{b}$ & 0.31 & $\nearrow^{\star *}$ \\
\hline $20: 2 n-6$ & $0.31 \pm 0.00$ & $0.52 \pm 0.02$ & $1.28 \pm 0.03$ & $0.31 \pm 0.00$ & $0.61 \pm 0.00$ & $0.90 \pm 0.54$ & $0.19 \pm 0.07^{a}$ & $0.30 \pm 0.04^{\mathrm{ab}}$ & $0.40 \pm 0.08^{b}$ & 0.25 & $\nearrow^{\star *}$ \\
\hline $20: 3 n-6$ & $0.66 \pm 0.06$ & $0.27 \pm 0.00$ & $0.41 \pm 0.03$ & $0.66 \pm 0.06$ & $0.50 \pm 0.01$ & $0.34 \pm 0.10$ & $0.27 \pm 0.04$ & $0.27 \pm 0.04$ & $0.27 \pm 0.01$ & 0.22 & n.s. \\
\hline $20: 4 n-3$ & $0.24 \pm 0.00$ & $0.35 \pm 0.02$ & $0.27 \pm 0.03$ & $0.24 \pm 0.00$ & $0.28 \pm 0.00$ & $0.31 \pm 0.05$ & $0.07 \pm 0.03$ & $0.13 \pm 0.12$ & $0.09 \pm 0.05$ & 0.44 & n.s. \\
\hline $20: 4 n-6(A A)$ & $1.45 \pm 0.05$ & $2.33 \pm 0.01$ & $6.34 \pm 0.10$ & $1.45 \pm 0.05$ & $2.89 \pm 0.15$ & $4.33 \pm 2.84$ & $4.93 \pm 0.48^{a}$ & $5.74 \pm 0.55^{b}$ & $5.93 \pm 0.72^{b}$ & 6.85 & $\nearrow^{\star \star}$ \\
\hline 20:5n-3 (EPA) & $15.43 \pm 0.76$ & $22.19 \pm 0.04$ & $21.60 \pm 0.03$ & $15.43 \pm 0.76$ & $18.66 \pm 0.31$ & $21.89 \pm 0.41$ & $9.93 \pm 4.44$ & $5.98 \pm 0.94$ & $6.44 \pm 1.48$ & 8.16 & n.s. \\
\hline $22: 4 n-6$ & $0.12 \pm 0.01$ & $0.28 \pm 0.01$ & $0.31 \pm 0.11$ & $0.12 \pm 0.01$ & $0.21 \pm 0.00$ & $0.29 \pm 0.02$ & $0.79 \pm 0.08$ & $0.69 \pm 0.11$ & $0.78 \pm 0.04$ & 1.13 & n.s. \\
\hline $22: 5 n-3$ & $0.00 \pm 0.00$ & $0.43 \pm 0.08$ & $0.54 \pm 0.04$ & $0.00 \pm 0.00$ & $0.24 \pm 0.00$ & $0.49 \pm 0.08$ & $5.01 \pm 1.15$ & $4.31 \pm 0.57$ & $3.98 \pm 0.37$ & 4.77 & n.s. \\
\hline $22: 5 n-6$ & $0.00 \pm 0.00$ & $0.83 \pm 0.05$ & $0.36 \pm 0.03$ & $0.00 \pm 0.00$ & $0.30 \pm 0.00$ & $0.59 \pm 0.33$ & $0.51 \pm 0.11$ & $1.61 \pm 0.54$ & $1.39 \pm 0.29$ & 0.86 & n.s. \\
\hline 22:6n-3 (DHA) & $0.51 \pm 0.01$ & $19.69 \pm 0.03$ & $22.81 \pm 0.02$ & $0.51 \pm 0.01$ & $10.88 \pm 0.02$ & $21.25 \pm 2.20$ & $17.22 \pm 6.14^{\mathrm{a}}$ & $24.15 \pm 2.22^{\mathrm{ab}}$ & $26.31 \pm 0.97^{b}$ & 25.47 & $\nearrow^{\star \star}$ \\
\hline 24:0 & $0.20 \pm 0.02$ & $0.15 \pm 0.01$ & $0.14 \pm 0.03$ & $0.20 \pm 0.02$ & $0.17 \pm 0.00$ & $0.14 \pm 0.01$ & $0.42 \pm 0.18$ & $0.37 \pm 0.12$ & $0.37 \pm 0.17$ & 0.49 & n.s. \\
\hline Saturated & 35.3 & 30.1 & 28.4 & 35.32 & 32.30 & 29.28 & 35.33 & 34.50 & 33.65 & 33.30 & n.s. \\
\hline Monounsaturated & 26.0 & 20.1 & 14.5 & 26.03 & 21.66 & 17.30 & 21.45 & 18.67 & 18.77 & 16.35 & n.s. \\
\hline Polyunsaturated & 38.7 & 49.8 & 57.1 & 38.65 & 46.04 & 53.42 & $43.22^{a}$ & $46.83^{a b}$ & $47.58^{b}$ & 50.35 & $\nearrow^{* *}$ \\
\hline$n-3$ & 17.2 & 44.2 & 46.4 & 17.20 & 31.24 & 45.29 & 32.93 & 35.18 & 37.24 & 39.40 & $\nearrow^{*}$ \\
\hline$n-6$ & 21.5 & 5.6 & 10.7 & 21.46 & 14.79 & 8.13 & 10.29 & 11.65 & 10.34 & 10.95 & n.s. \\
\hline n-3 HUFA & 16.2 & 42.6 & 45.2 & 16.18 & 30.06 & 43.94 & 32.22 & 34.56 & 36.82 & 38.83 & $\nearrow^{\star}$ \\
\hline DHA/EPA & 0.03 & 0.89 & 1.06 & 0.03 & 0.58 & 0.97 & $2.11^{a}$ & $4.16^{b}$ & $4.22^{b}$ & 3.12 & $\lambda^{*}$ \\
\hline DHA/ARA & 0.35 & 8.45 & 3.60 & 0.35 & 3.76 & 4.90 & 3.43 & 4.23 & 4.46 & 3.72 & n.s. \\
\hline$n-3 / n-6$ & 0.80 & 7.87 & 4.36 & 0.80 & 2.11 & 5.57 & 3.27 & 3.04 & 3.63 & 3.60 & n.s. \\
\hline Total lipids & 10.39 & 7.99 & 6.70 & 10.39 & 8.87 & 7.35 & 12.99 & 12.17 & 12.56 & 15.85 & n.s. \\
\hline
\end{tabular}

Sample size: 10-20 mg dry weight. J-T test: Jonckheere-Terpstra test. The medians of the groups ascend ( $\uparrow$ ) or descend ( $\downarrow)$ in the order specified by the coding variable (order: increasing proportions of mysidaceans in the diet - A, AM, and M). Seahorse juveniles: different superscript letters indicate significant differences. W, newborn from a pregnant wild male; n.s., not significant. 
TABLE 3 | Isotope profiles $\left(\delta^{13} \mathrm{C} \%\right.$ and $\delta^{15} \mathrm{~N} \%$ ) in dorsal fins (start and end of the experimental breeding period) of Hippocampus guttulatus breeders fed on diets A (Artemia), AM (Artemia + Mysidacea) and M (Mysidacea), and in newborn juveniles.

\begin{tabular}{|c|c|c|c|c|c|}
\hline & \multirow[b]{2}{*}{ Group } & \multicolumn{2}{|c|}{ Breeder's dorsal fin } & \multirow[b]{2}{*}{$\Delta \delta$} & \multirow[t]{2}{*}{ Newborn juveniles Pooled batches } \\
\hline & & Initial & Final & & \\
\hline \multirow[t]{4}{*}{$\delta^{13} \mathrm{C}$} & $A$ & $-17.37 \pm 1.47(7)$ & $-13.99 \pm 1.05(7)$ & 2.97 & $-13.86 \pm 1.64(4)$ \\
\hline & AM & $-16.98 \pm 2.00(11)$ & $-17.18 \pm 1.64(11)$ & -0.20 & $-17.31 \pm 1.13(6)$ \\
\hline & $\mathrm{M}$ & $-16.04 \pm 0.87(10)$ & $-18.03 \pm 1.38(10)$ & -1.89 & $-16.80 \pm 1.27$ (3) \\
\hline & Wild & $-16.00 \quad-(1)$ & $-18.00 \quad-(1)$ & - & $-14.10 \quad-(1)$ \\
\hline \multirow[t]{4}{*}{$\delta^{15} \mathrm{~N}$} & A & $11.94 \pm 0.81(7)$ & $10.28 \pm 0.91(7)$ & -1.43 & $11.21 \pm 0.88(4)$ \\
\hline & AM & $12.79 \pm 1.11$ & $13.50 \pm 0.98$ & 0.88 & $14.96 \pm 1.50(6)$ \\
\hline & $\mathrm{M}$ & $12.19 \pm 0.72(10)$ & $14.74 \pm 0.86(10)$ & 2.58 & $14.28 \pm 2.35(3)$ \\
\hline & Wild & $12.00-(1)$ & $14.40-(1)$ & - & 14.10 \\
\hline
\end{tabular}

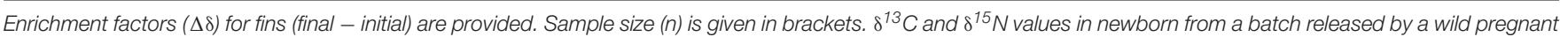
male are also given for comparative purposes.

TABLE 4 | Batches produced, batch size, standard length (mm), dry weight (mg), and survival percentage (7 DAR) of newborn juveniles released by Hippocampus guttulatus breeders fed on diets A (Artemia), AM (Artemia + Mysidacea), and M (Mysidacea).

\begin{tabular}{|c|c|c|c|c|c|c|}
\hline Diet & $\begin{array}{l}\text { Batches } \\
\text { produced }\end{array}$ & $\begin{array}{c}\text { Total } \\
\text { juveniles }\end{array}$ & $\begin{array}{l}\text { Batch size } \\
\text { Mean sd }\end{array}$ & $\begin{array}{l}\text { Length }(\mathrm{mm}) \\
\text { Mean sd }\end{array}$ & $\begin{array}{c}\text { Dry weight (mg) } \\
\text { Mean sd }\end{array}$ & $\begin{array}{c}\text { Survival (\%) } \\
\text { Mean sd }\end{array}$ \\
\hline A & 4 & 534 & $134^{a} \pm 83$ & $12.9^{\mathrm{a}} \pm 0.7$ & $0.60^{a} \pm 0.16$ & $94.0^{\mathrm{a}} \pm 5.3$ \\
\hline AM & 7 & 1,416 & $202^{a} \pm 82$ & $14.7^{b} \pm 0.7$ & $0.74^{\mathrm{a}} \pm 0.11$ & $86.9^{a} \pm 9.5$ \\
\hline $\mathrm{M}$ & 3 & 248 & $84^{a} \pm 72$ & $14.1^{b} \pm 0.2$ & $0.73^{a} \pm 0.06$ & $61.4^{a} \pm 19.2$ \\
\hline W & 1 & - & 210 & 14.1 & 0.78 & 94.9 \\
\hline
\end{tabular}

W: Newborn from a wild pregnant male. Different letter superscripts indicate significant differences $(P<0.05)$.

filament) (Figures 5A,B,D). In the longitudinal sections of TEM micrographs of skeletal muscle sections, the myofibrils appeared tightly packed in the scarce amount of cytoplasm. The nuclei were located in the peripheral layer of the fiber and mitochondria beneath the sarcolemma and among the myofibrils. Besides, the regular repeating pattern of myofilaments in the myofibrils were detected displaying dense $\mathrm{Z}$ lines, forming a regular zigzag (Figures 5A,B,D) at the center of the light I bands. The A bands showed a central light $\mathrm{H}$ zone divided by a dark $\mathrm{M}$ line (Figure 5A). In addition, the organization of the sarcoplasmic reticulum and the sarcoplasmic triad, consisting of two terminal cisterns and the transverse tubule $\mathrm{T}$ (formed by the invagination of the sarcolemma) were also observed (Figures 5A,C). Scattered satellite cells surrounded by volumetrically modest cytoplasm were often seen in muscle tissue (Figures 5E,6B).

In the cross sections, the disposition of the two sets of myofilaments in different bands of the sarcomere were analyzed. The myofibrils were well delineated by the close apposition of the sarcoplasmic elements (Figures 6A,B). The nuclei were located in the peripheral layer of the fiber and mitochondria beneath the sarcolemma and among the myofibrils.

The general morphology observed in newborn released by males from diet $\mathrm{A}$ appeared similar to the other groups ( $\mathrm{M}$ and AM). However, some ultrastructural muscle changes were noticed. In particular, group A displayed regressive changes in some muscle fibers characterized by a disarrangement of myofibrils (Figure 5B), with evident myofibrillary interstitial spaces. Besides, a discontinuity of the sarcolemma and myelin-like bodies were present (Figure 6C). In addition, a disorganization of the sarcoplasmic elements and of the invagination of the sarcolemma (i.e., tubules $T$ ) was also noticed. An interruption of the $\mathrm{Z}$ line was also occasionally evidenced (Figures 5E,F) and neuromuscular junctions were observed between motor nerve endings and muscle fibers. Particularly, the terminal axons of the motor neuron were spherical or oval in shape and fit into smooth depressions in each muscle fiber (Figures 6D-F). At the presynaptic zone, several mitochondria and small clear synaptic vesicles were noticed. Other morphological alteration were not detected at the level of the above structures.

\section{DISCUSSION}

\section{Breeding Performance}

In this study, the isotopic results achieved in dorsal fins of the seahorse $H$. guttulatus confirmed the effective assimilation of experimental diets by breeders, with effects on average isotopic signatures and FA profiles in newborn seahorses across groups. The overall breeding performance (extension of the effective breeding period, batches produced, and newborn released) resulted enhanced in parents fed on the mixed diet AM (non-enriched Artemia and mysidaceans), suggesting a better nutritional condition than in groups A and M. Unexpectedly, the use of mysidaceans as only prey (diet $M$ ) resulted in the worse breeding success among the three experimental diets.

Brood size in some seahorse species (e.g., H. kuda and $H$. erectus) has been related to the length of brood pouches 
of males and trunk of females (Dzyuba et al., 2006; Lin et al., 2012). The newborn size might be correlated to brood size, gestation time and nutrient supply in the same males and females' investment (Lin et al., 2008b, 2012). Besides this, larger H. erectus males (larger brood pouches) do not produce larger broods, and male size can be positively correlated with juvenile size (Lin et al., 2012). In H. guttulatus, it has been pointed out that the size of newborn seahorses can be, in part, paternally determined (limited

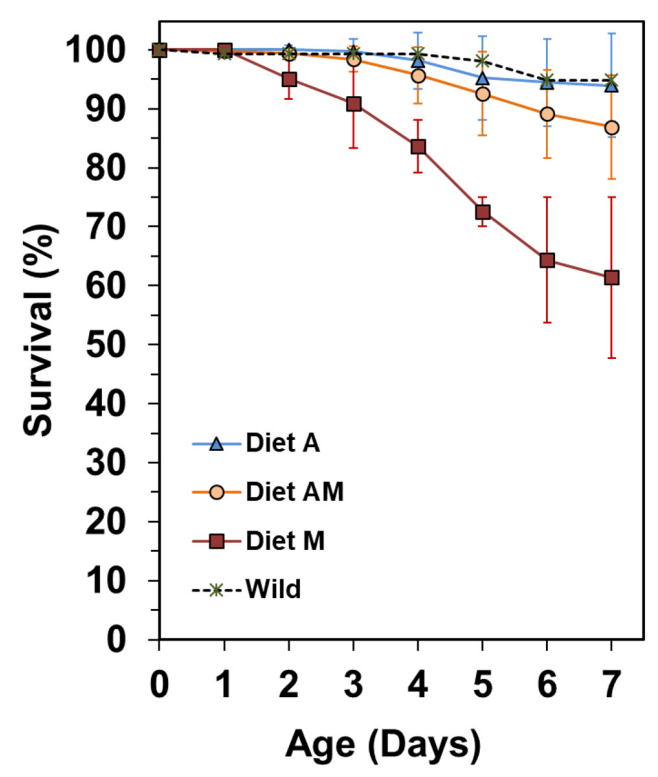

FIGURE 2 | Initial survival of newborn seahorses released by a wild male and by captive males fed on diets $\mathrm{A}, \mathrm{AM}$, and $\mathrm{M}$. carrying capacity of the male), as male size is negatively correlated with embryo density and positively correlated with newborn size (Faleiro et al., 2016). As breeders average size did not differ across our experimental groups, we assume that differences between treatments in our study were due to dietary dissimilarities. Differences in the capability of seahorses to digest and assimilate a given prey is another subject to consider when assessing diet quality. The monitoring of prey in feces of $H$. guttulatus by $18 \mathrm{SrDNA}$ amplification showed that gut passage times of crustaceans (Artemia, Palaemonetes, and mysidaceans Leptomysis sp., and Siriella sp.) are species-dependent (longer passages times in mysidaceans), probably due to differences in their digestibility (lower digestibility in Palaemonetes) (Corse et al., 2015).

Mysidaceans have been considered an excellent prey for the on-growing and breeding of some seahorse species (e.g., H. abdominalis and H. hippocampus). Otero-Ferrer et al. (2012) studied the effect of feeding $H$. hippocampus breeders exclusively on Artemia enriched with DHA or captured mysids (Leptomysis sp.). The authors reported better results on reproduction (spawning events and brood size) and newborn size in breeders fed on mysids, presumptively due to a higher nutritional quality of mysidaceans (basically in DHA content). Those results strongly agree with those with diet AM, but not with the poor results achieved with diet $M$. we also recommended (but not tested) the use of a mixed diet including Artemia and mysids.

In the present study, premature newborn release or egg clutch dropping were not observed. Such issues were observed in previous studies performed on $H$. hippocampus fed on Artemia (Otero-Ferrer et al., 2012) or commercial mysidaceans (i.e., much lower DHA and HUFA levels than in the present study) (Saavedra et al., 2015) and in H. guttulatus fed on suboptimal quality of Artemia (i.e., high lipid and low DHA content) (Planas et al., 2009b, 2010). In the later, the issue was solved by optimizing

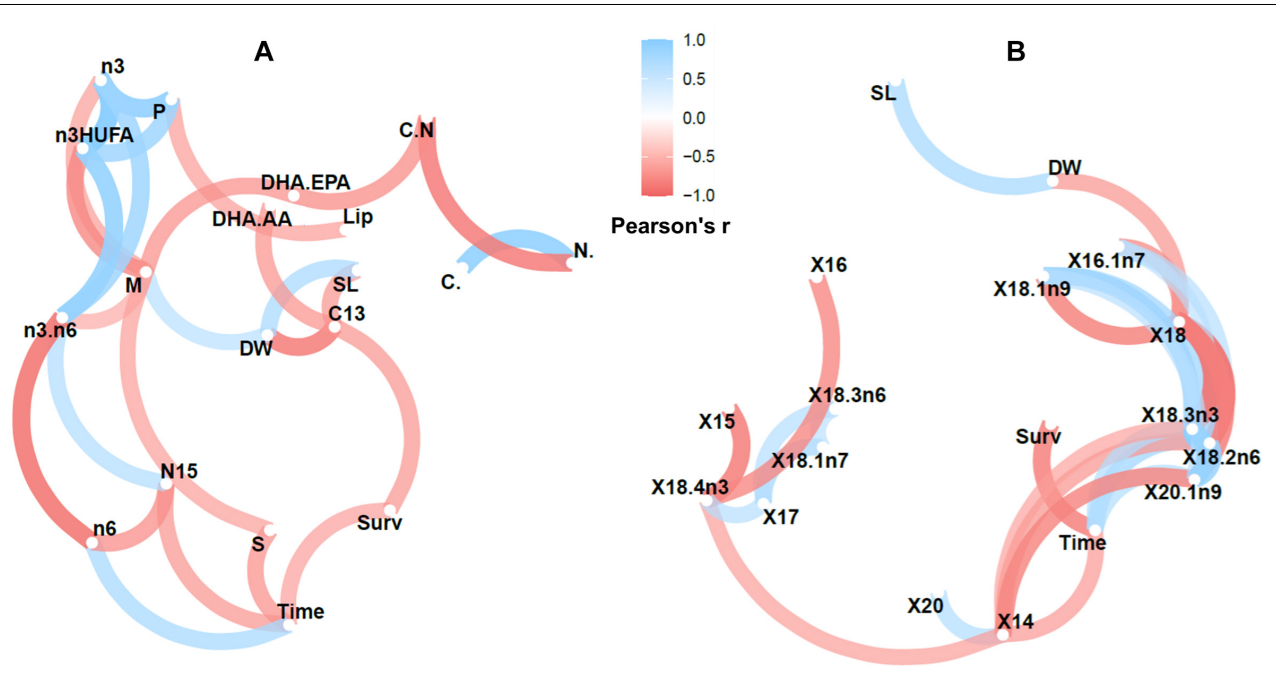

FIGURE 3 | Correlation network plots for newborn seahorses (Diet AM) showing the more highly correlated variables (Pearson's $r>0.6)$, which appear closer together and joined by stronger paths. Paths are also colored by their sign (blue for positive and red for negative). The proximity of the points were determined using multidimensional clustering. Original variable names were modified by R software. Variables: (A) time (days elapsed since the onset of the breeding period), SL, W, Survival at 7 DAR (Surv), total C (C.), total $N\left(N\right.$.), C/N, $\delta^{13} \mathrm{C}(\mathrm{C} 13), \delta^{15} \mathrm{~N}(\mathrm{~N} 15)$, total lipids (Lip.DW), saturated FA (S), monounsaturated FA (M), polyunsaturated FA (P), n-3 HUFA, n-3 FA, n-6 FA, n-3/n-6 (n3.n6), DHA/EPA (DHA.EPA) and DHAAA (DHA.AA); (B) time, SL, W, Survival at 7 DAR (Surv) and individual FA. 


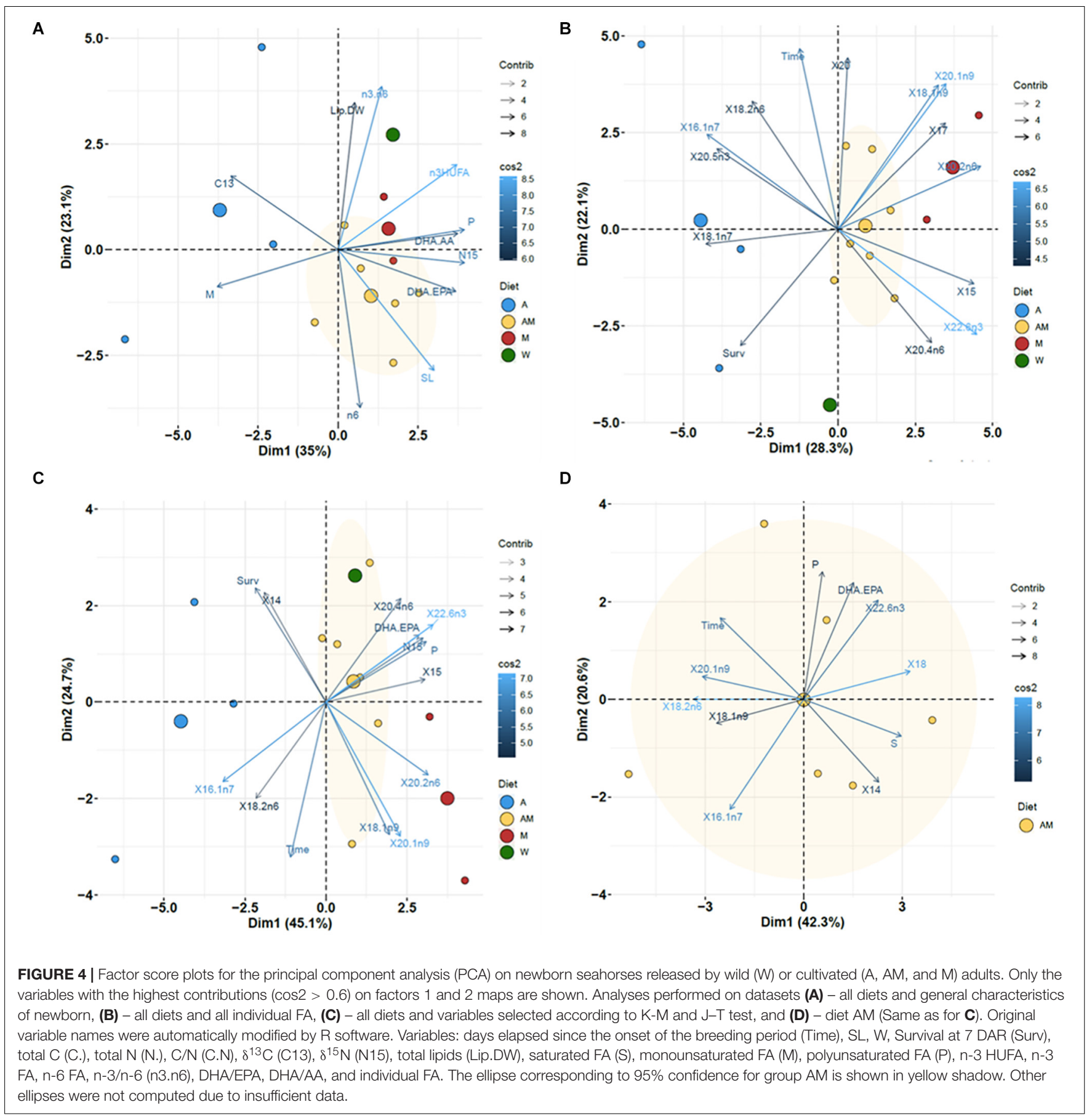

DHA and EPA content in Artemia (Planas et al., 2017b) and isolating pregnant males a few days prior to newborn release (Olivotto et al., 2011b).

Small initial lengths and reduced batch sizes in newborn from group A were accompanied by high survivals at 7 DAR. This result was unexpected as newborn survival commonly depends on the dietary quality provided to broodstock. Interestingly, it has been reported in $H$. reidi that reducing the nutritional quality of a male's diet since one month before conception resulted in abnormally large and heavy newborns with extremely reduced survivals, independently of the dietary quality in females (Otero-Ferrer et al., 2016). These findings partially agree with those reported in the pipefish Syngnathus typhle, in which a higher nutritional condition in males brooding heavier embryos was correlated with a higher embryo survival (Sagebakken et al., 2017).

Even though the growth of adult $H$. guttulatus fed on Artemia may be satisfactory (Planas et al., 2008, 2009a; Segade et al., 2015), it seems that its high lipid content and suboptimal FA profile might result in an excessive accumulation of lipids in the liver 


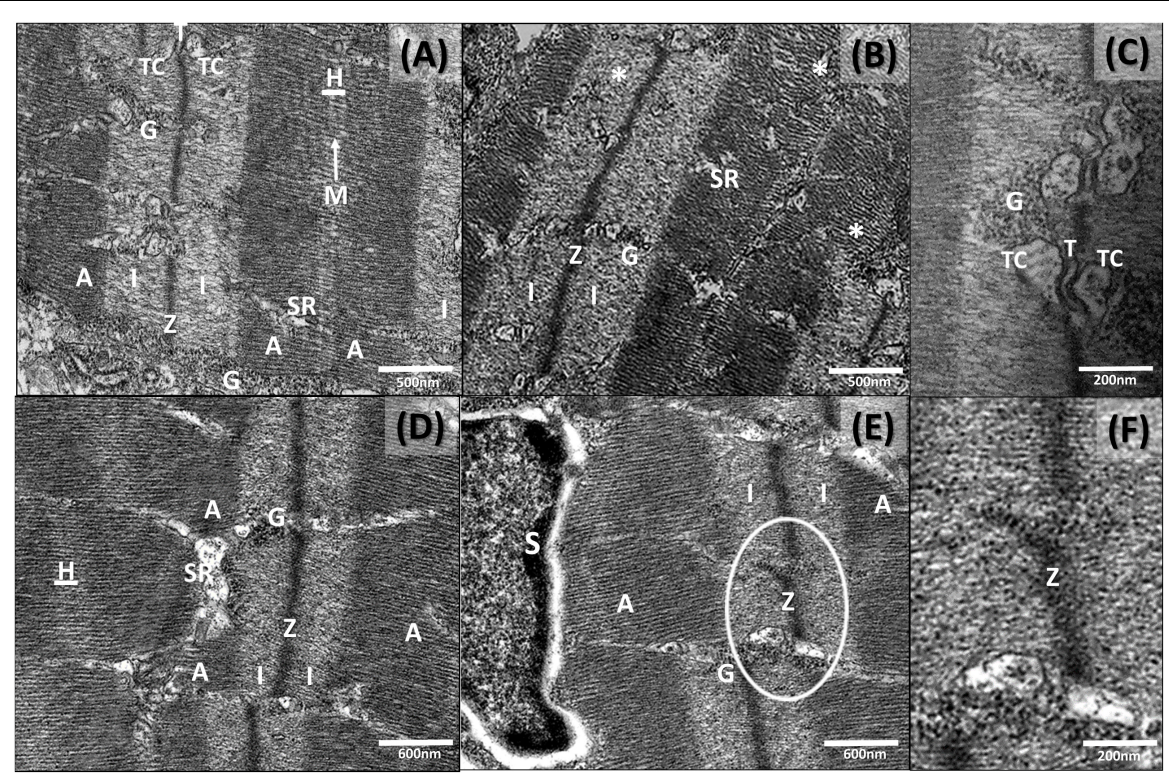

FIGURE 5 | Transmission electron micrographs of newborn seahorse muscle (Iongitudinal sections) from groups M, AM and A. (A) Group AM: normal sarcomere with light isotrope band (I); Z line; dark anisotrope band (A), central H-zones and in the middle M lines (arrow); triad located at the Z line level. (B) Group A: myofibrils with a slight disarrangement. (C) Group AM: higher magnification. Note tubule T between two terminal cisternae close to each other just forming the longitudinal connection. (D) Group M: a regular zigzag configuration of the $Z$ line of the sarcomere. (E) Group A: interruption of $Z$ line (circled). (F) Higher magnification interruption of above circled Z line. SR, sarcoplasmatic reticule; G, glycogen; Tc, terminal cisternae; T, Tubule T; S, satellite cells.

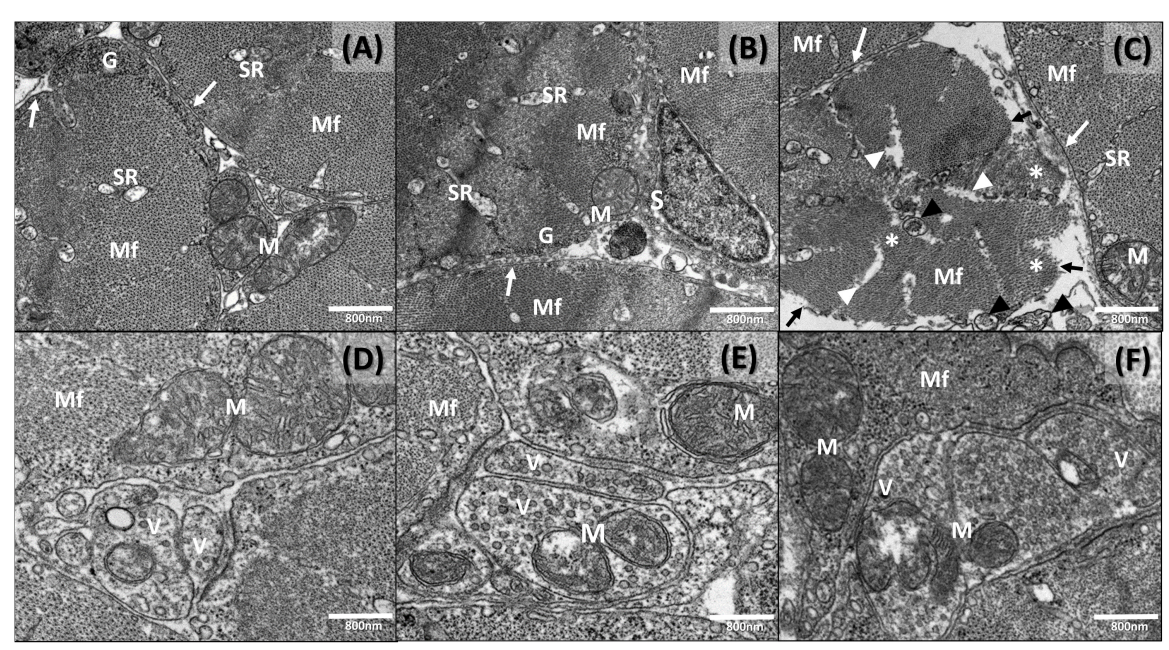

FIGURE 6 | Transmission electron micrographs of newborn seahorse muscle (cross sections) from groups AM, M, and A. (A) Group AM: normal structure. (B) Group M: normal structure. (C) Group A: disarrangement of myofibrils (asterisks); myofibrillary interstitial spaces (white arrow heads); discontinuity of the sarcolemma (black arrows); myelin-like bodies (black arrow heads). (D) Group AM: nerve ending. (E) Group M: nerve ending. (F) Group A: nerve ending. S, satellite cells; SR, sarcoplasmic reticule; Sarcolemma (white arrows); Mf, myofibrils; M, mitochondria; G, glycogen; V, vesicles.

and an abnormal (not necessarily pathological) displacement of hepatocytes core to the periphery of the cells (Segade et al., 2016). The presence of ultrastructural muscle alterations at the level of the contractile component and presence of myelin-like bodies (expression of the lysis of the membranes involved by the regressive phenomena) in newborns released by males fed on diet A can be related to some nutritional deficiencies in unenriched Artemia. Polyunsaturated fatty acids (PUFAs) are essential FAs in regulating normal growth and development in many fish species (Anderson et al., 1990; Olivotto et al., 2011a) and promoting muscle fiber development (Cong-cong et al., 2019). Specifically, DHA is a structural key component of cell membranes involved in their biosynthesis (Olivotto et al., 2011a; Randazzo et al., 2018). The low levels of DHA in diet A might thus be responsible for the alterations found in some muscle fibers. Furthermore, an interruption, observed only occasionally of the $\mathrm{Z}$ line, could 
be the expression of the structural disarrangement of myofibrils demonstrated in muscle fibers with regressive phenomena.

The supposed superior quality of several small species of marine crustaceans (e.g., amphipods and mysidaceans) over Artemia has been reported in seahorse culture (Palma et al., 2008; Woods, 2009; Otero-Ferrer et al., 2012; Buen-Ursue et al., 2015; Vargas-Abúndez et al., 2018). Those sources are among the mostly consumed preys by wild seahorses (Manning et al., 2019). However, the main dietary sources for $H$. guttulatus adults in our nearby region (NW Iberian Peninsula) are amphipoda (caprellids and gammarids), whereas mysidaceans are insignificant prey in the bulk diet composition (Valladares et al., 2016). We recently demonstrated that diets including mysidaceans (alone or mixed with Artemia) provide the best trophic enrichment factors (laboratory derived) to infer the composition of bulk diet in wild syngnathids by means of isotopic signatures (Planas et al., 2020). Hence, even though mysidaceans might be considered a high quality prey for some seahorse species, it is very likely not suitable for breeding $H$. guttulatus when administered as the sole prey. Unfortunately, nutritional requirements in seahorses are unknown, and provision of suitable food sources for ex-situ culture often represents a serious constraint (Chang and Southgate, 2001) as not all species seem to have the same nutritional needs, as suggested by inter-specific differences in FA profiles (Lin et al., 2008a). Consequently, mixed diets (present study) and/or dietary supplementation would potentially reduce some nutritional deficiencies of single prey (Palma et al., 2012, 2017).

\section{Breeding Strategy}

Seahorses are synchronous batch spawners, as several oocyte populations are present during the reproductive season and clutches of oocytes develop, mature, and are released simultaneously (Fernández-Palacios et al., 2011). During the last part of the secondary growth of oocytes (vitellogenesis), lipids and yolk proteins are incorporated and stored in large amounts in the yolk. That process and further embryogenesis of fertilized eggs in males cyclically occurs along the breeding season, requiring a continuous expenditure of energy and nutrients. Seahorse females and males are time-synchronized for egg batch transfer from females to males and newborn release in males, and in $H$. guttulatus kept at $19-20^{\circ} \mathrm{C}$ both processes occur at 25-27 days time-intervals (Planas et al., 2010). On this regard, it is very important to ascertain the origin (capital, income or mixed capital-income reproduction strategy) of the energy and nutrients necessary for reproduction (Williams et al., 2017) and to evaluate whether and when egg/fry composition can be affected by the type of diet provided. Hence, the identification of both diet quality and effective feeding periods (the time period needed to change the biochemical composition of eggs/fry) for optimum broodstock performance is of pivotal importance in enhancing newborn quality (Fernández-Palacios et al., 2011; Griffen, 2018). The present study and the pattern of isotopic changes discussed elsewhere (Planas et al., 2020) suggest that the reproduction type followed by $H$. guttulatus corresponds to a mixed capital-income strategy. This strategy usually implies a progressive drop in newborn quality in successive batches
(McBride et al., 2015; Griffen, 2018). In order to properly assess the breeding strategy followed by $H$. guttulatus, the effects of experimental diets must be analyzed over the entire breeding period. Given that the pattern of change in the biochemical components analyzed in newborn did not follow a mathematical model for fitting, the effective feeding periods were inferred from the smoothed trends in the most remarkable components along the breeding period (particularly for group AM) (Figure 7). In most cases, trend inflexions occurred within the period comprising 100 and 140 days, depending on the variable and seahorse group considered. We identified three stages along the whole breeding period:

- Stage 1 (mixed capital-income sources): progressive changes occur since the dietary shift at the onset of the breeding season. Energy and nutritional resources would mostly originate from resources gained prior to the breeding period (capital breeding), accompanied by an increasing use of sources derived from the experimental diet (income breeding). This stage would extend until days 100-140 since the onset of the breeding period.

- Inflection period (income sources): this is a transitory period indicating the end of the capital-income breeding strategy and the use exclusively of resources from the experimental diet. In this period, differences among treatment were clearly perceptible.

- Stage 2 (income sources and exhaustion of body reserves): in most cases, differences among groups increased or decreased (depending on the variable considered) beyond the inflection period. Maximal divergences between treatments were reached during this period, notably by the end of the stage. The trend followed by certain variables (e.g., DHA and DHA/EPA) in late newborn batch releases suggests a more or less intense exhaustion of body resources, accompanied by decreases in survivals at $7 \mathrm{DAR}$ and newborn size. This statement is also supported by the trends in newborn isotopic signatures (Planas et al., 2020).

Fry quality can be manipulated to a certain extend by modifying the nutritional composition of the diet during the breeding season of fishes (Fernández-Palacios et al., 2011) including seahorses (Otero-Ferrer et al., 2020). However, it is also important to assess the effect of preconception diet on reproduction success and the contribution of males and females, as reported by Otero-Ferrer et al. (2016) in H. hippocampus. According to our above hypothesis on the stages recognized along the breeding season, the diet provided preceding the reproduction season would contribute for a certain period to the initial composition and quality of $H$. guttulatus newborn. Hence, the initial quality of eggs/newborn could be improved by feeding the breeders on a high quality diet for at least 3 months in advance of the onset of the breeding season, which is in agreement with previous findings in the tropical species $H$. reidi (Planas and Chamorro, 2019). That finding is of primary importance to female diets as it is noteworthy that embryos are mostly dependent on maternal nutrition (yolk quality) until later stages 

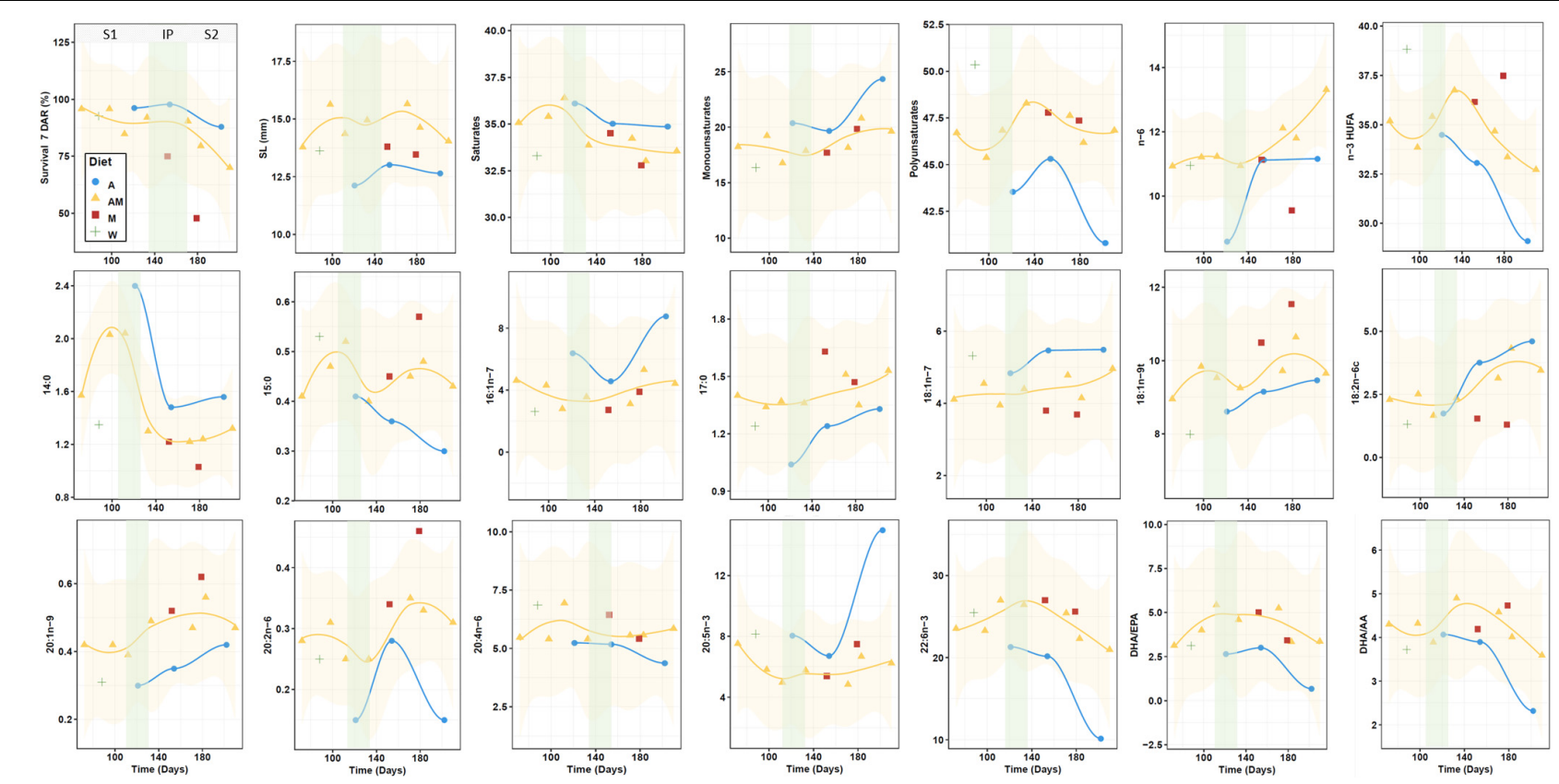

FIGURE 7 | Progressive changes in survival at 7 DAR, length (SL), fatty acids (area percentage), and FA ratios along the breeding period in newborn released by seahorses (Wild and groups A, AM and M). Smoothed trends are shown for groups AM (95\% confidence intervals also shown) and A. Green shadowed areas show inflection periods indicating a remarkable change (transition from stage 1 to stage 2). Stages: S1 (Stage 1), IP (Inflection period), and S2 (Stage 2).

of development, when the embryos are mostly dependent on paternal contribution (Otero-Ferrer et al., 2020).

\section{Newborn Composition}

Breeders diet must be optimized to ensure good early development (i.e., growth, survival, and health) (Izquierdo et al., 2001; Migaud et al., 2013). Currently, nutrients requirements are rather well known in many marine species with interest in ornamental trade, and optimal dietary formulations are available (Craig et al., 2017). However, there are two main issues in the feeding of seahorses in captivity: the lack of knowledge on their nutritional needs and the rejection of inert formulated diets (Olivotto et al., 2011b; Palma et al., 2012; Planas et al., 2017a). As the broodstock diet is strongly reflected in the composition of eggs/fry, particularly for lipids (Wiegand, 1996), the composition of eggs or fry can be used as a proxy to infer nutritional requirements in fishes to improve breeding success (Sargent et al., 1989, 1999; Rainuzzo, 1993; Fernández-Palacios et al., 1995; Rainuzzo et al., 1997). The content in lipids and the FA profiles of $\mathrm{H}$. guttulatus eggs under different dietary regimes were reported by Planas et al. $(2008,2010)$ and Faleiro and Narciso (2010). Essentially, FA profiles in eggs and newborn do not differ significantly when the content is referred to relative percentage of total FA, but they markedly differ when the content is given as dry weight percentage (Faleiro and Narciso, 2010). In the present study, we focused exclusively on newborn, including a batch released by a wild pregnant male for comparative purposes.

The similarity between the wild batch (released early in the season) and the early and mid-term batches released from group AM was mainly due to DHA, total polyunsaturated
FA, $\delta^{15} \mathrm{~N}$, survival at 7 DAR, DHA/EPA ratio, AA and, to a lesser extent, to minority $20: 1 \mathrm{n}-9$ and $20: 2 \mathrm{n}-6(<1 \%)$. The DHA/EPA ratio reflected the higher and more stable content in DHA thorough the breeding season, compared to treatment A. The essentiality of DHA, EPA, and AA in early developmental stages of marine fish has been previously discussed in depth (Rainuzzo, 1993; Bromage, 1995; Wiegand, 1996; Rainuzzo et al., 1997; Estévez et al., 1999; Tocher, 2010). There is no doubt about the nutritional essentiality of certain HUFAs in marine fish. These FA are important sources of energy in fish during early embryogenesis (Sargent et al., 1999) when DHA and AA are highly conserved in most teleost (Watanabe et al., 1989). However, Faleiro and Narciso (2010) analyzed the lipid and FA dynamics during early development of $H$. guttulatus (breeders fed on adult Artemia; Artemia diet not provided) and reported that EPA, DHA, and palmitic acid were not preferentially retained in embryos as they constitute the main energy sources, with EPA being catabolized at a high rate. Consequently, an exceptionally low lipid content (5.0\% DW) and extremely low EPA levels (5.0\%) were reported in newborn. Compared to that study, EPA content and total lipids in newborn from our study were two-fold higher, in agreement with previous results in freshly released eggs (Planas et al., 2008, 2010).

In spite of the extremely low levels of DHA in diet A, its average content in newborns was high (with a sharp decrease in late batches) although lower than in groups AM and M. This finding indicates the essentiality of DHA in seahorses. Overall, FA profile and DHA/EPA ratio in newborns released from the wild male showed a higher similarity with newborns released by males fed on diets including mysidaceans. Hence, the 
variable effect of breeder's diet on the allocation of FA resources in newborn from different experimental assays is confirmed in H. guttulatus, deserving further attention, especially with regard to dietary DHA requirements and further effects on survival and size of newborn.

Higher dietary contents in total n-3 HUFA and DHA does not necessarily imply higher quality. Excessive levels of dietary n-3 HUFA can reduce eggs production and survival, and cause yolk sac hypertrophy in fish larvae (Fernández-Palacios et al., 1995). As the TEM did not show any morphological alteration in tissues of newborn from diet M, we suspect that n-3 HUFA and DHA levels in diet $M$ were below detrimental levels, and that the low breeding success in that treatment was due in part to energetic and/or nutritional dietary deficiencies. It is known that egg viability may decrease in lower quality diets (Saavedra et al., 2015) which is in agreement with the reduced newborn production in diets $\mathrm{A}$ and $\mathrm{M}$. As eggs dropping did not occur in our study and female-male egg transfers were not checked, viability in eggs transferred to males is not available. Hence, the reasons for that low performance are uncertain. In addition to potential negative effects of low quality diets on mating displays, a drop in reproductive success due to the strategy of cryptic choice should not be discarded. According to this strategy, males could increase rates of offspring abortion in pregnancies to absorb nutrients nutrients for future reproductive opportunities (Paczolt and Jones, 2010; Sagebakken et al., 2010).

\section{CONCLUSION}

In the experimental study presented here, isotopic signatures of experimental diets supplied during the breeding season were reflected in breeder's dorsal fins (efficient assimilation of diets) and subsequently in newborn, with higher $\delta^{15} \mathrm{~N}$ signals in breeders and newborn from the diets including mysidaceans. Monospecific diets including Artemia or mysidaceans very likely suffered from nutritional deficiencies, reflected in morphological alterations of the muscle tissue or abnormal early mortalities in newborn. Those deficiencies seemed to be overcome with the mixed diet AM (unenriched Artemia and mysidaceans), which provided the highest overall breeding success and reasonable FA profiles, and better resembled newborn from a wild male. However, special attention deserve the progressive changes in FA profiles along the breeding season, resulting in a decrease in newborn performance. Considering the time required for a diet to be reflected in newborn, we recommend that $H$. guttulatus breeders be fed on a high quality diet at least 3 months in advance of the onset of the breeding period.

In order to further optimize captive breeding and rearing of seahorses, further research should focus on wild populations with particular emphasis on broodstock feeding habits, on how feeding preferences possibly change during the breeding season and on potential shifts depending on the geographical distribution of the fish. Data collected from the wild will help scientist in the selection of the more suitable diet able to sustain the best egg and fry quality.

\section{DATA AVAILABILITY STATEMENT}

The datasets analyzed for this study can be found in the Pangaea collection (https://doi.pangaea.de/10.1594/PANGAEA. 919218). Data not listed in this collection is available from the authors upon reasonable request.

\section{ETHICS STATEMENT}

The animal study was reviewed and approved by Regional Government Xunta de Galicia (REGA ES360570202001/15/FUN/BIOL.AN/MPO01).

\section{AUTHOR CONTRIBUTIONS}

MP as leading author has done the conception of the work, breeding and rearing, sampling, lipid and stable isotope analysis, interpretation of data, and most part in drafting. IO and RL assisted in manuscript writing. MG was responsible for fatty acid analysis. RL and MZ were responsible for TEM and this part of the draft. All authors revised the manuscript. All authors contributed to the article and approved the submitted version.

\section{FUNDING}

This study was financially supported by the Spanish Government with Project Hippoeco (Ref. CGL2015-68110-R, Ministerio de Ciencia, Innovación y Universidades and Fondos FEDER).

\section{ACKNOWLEDGMENTS}

We acknowledge support of the publication fee by the CSIC Open Access Publication Support Initiative through its Unit of Information Resources for Research (URICI). We are grateful to Alexandro Chamorro, Alex Paltrinieri, David Costas, Isabel Medina, and the staff of the Aquaria Service at IIM-CSIC for assistance in the maintenance of seahorses in captivity and technical support. We are also grateful to the Regional Government Xunta de Galicia for providing the permission for the capture of wild adult seahorses Hippocampus guttulatus. Finally, we are very grateful to Sergio Picazo (https://sergiopicazo.com/) for providing usage rights of seahorse illustration in Figure 1.

\section{SUPPLEMENTARY MATERIAL}

The Supplementary Material for this article can be found online at: https://www.frontiersin.org/articles/10.3389/fmars.2020. 00638/full\#supplementary-material 


\section{REFERENCES}

Adams, M. B., Powell, M. D., and Purser, G. J. (2001). Effect of acute and chronic ammonia and nitrite exposure on oxygen consumption and growth of juvenile big bellied seahorse. J. Fish Biol. 58, 848-860. doi: 10.1111/j.1095-8649.2001. tb00535.x

Anderson, G. J., Connor, W. E., and Corliss, J. D. (1990). Docosahexaenoic acid is the preferred dietary n-3 fatty acid for the development of the brain and retina. Pediatr. Res. 27, 89-97. doi: 10.1203/00006450-199001000-00023

Binh, M. N., and Serrano, A. E. (2012). Optimum level of fish liver oil as enrichment for Artemia fed to the tiger tail seahorse Hippocampus comes for reproduction and juvenile survival. AACL Bioflux 5, 249-258.

Blanco, A., Clamorro, A., and Planas, M. (2014). Implications of physical key factors in the early rearing of the long-snouted seahorse Hippocampus guttulatus. Aquaculture 433, 214-222. doi: 10.1016/j.aquaculture.2014.06.019

Blanco, A., and Planas, M. (2015). Mouth growth and prey selection in juveniles of the European long-snouted seahorse, Hippocampus guttulatus. J. World Aquac. Soc. 46, 596-607. doi: 10.1111/jwas. 12240

Bligh, E. G., and Dyer, W. J. (1959). A rapid method of total lipid extraction and purification. Can. J. Biochem. Physiol. 37, 911-917. doi: 10.1139/o59-099

Boisseau, J. (1967). Les Regulations Hormonales de L'incubation chez un Vertebré Male: Recherches sur la Reproduction de l'Hippocampe. Ph.D. thesis, Université de Bordeaux, Bordeaux.

Bromage, N. R. (1995). "Broodstock management and seed quality - general considerations," in Broodstock Management and Egg and Larval Quality, eds N. R. Bromage and R. J. Roberts (London: Blackwell), 1-24.

Brooks, S., Tyler, C. R., and Sumpter, J. P. (1997). Egg quality in fish: what makes a good egg? Rev. Fish Biol. Fish. 7, 387-416. doi: 10.1023/A:1018400130692

Buen-Ursue, S. M. A., Azuma, T., Arai, K., and Coloso, R. M. (2015). Improved reproductive performance of tiger tail seahorse, Hippocampus comes, by mysid shrimp fed singly or in combination with other natural food. Aquacult. Int. 23, 29-43. doi: 10.1007/s10499-014-9795-1

Carcupino, M., Baldacci, A., Mazzini, M., and Franzoi, P. (2002). Functional significance of the male brood pouch in the reproductive strategies of pipefishes and seahorses: a morphological and ultrastructural comparative study on three anatomically different pouches. J. Fish Biol. 61, 1465-1480. doi: 10.1111/j.10958649.2002.tb02490.x

Chang, M., and Southgate, P. C. (2001). Effects of varying dietary fatty acid composition on growth and survival of seahorse, Hippocampus sp., juveniles. Aquarium Sci. Conserv. 3, 205-214. doi: 10.1023/A:1011363807074

Christie, W. W. (1982). Lipid Analysis: Isolation, Separation, Identification, and Structural Analysis. Oxford: Pergamon Press.

Cohen, F. P. A., Valenti, W. C., Planas, M., and Calado, R. (2016). Seahorse aquaculture, biology and conservation: knowledge gaps and research opportunities. Rev. Fish. Sci. Aquac. 25, 100-111. doi: 10.1080/23308249.2016 1237469

Cong-cong, W., Wen-bin, L., Yang-yang, H., Xi, W., Xiang-fei, L., Ding-dong, Z., et al. (2019). Dietary DHA affects muscle fiber development by activating AMPK/Sirt1 pathway in blunt snout bream (Megalobrama amblycephala). Aquaculture 518:734835.

Corse, E., Valladares, S., Planas, M., Chamorro, A., and Pintado, J. (2015). Analysis of the diet of the long-snouted seahorse Hippocampus guttulatus by $18 \mathrm{SrDNA}$ amplification of prey in faeces. Aquac. Nutr. 21, 528-540. doi: 10.1111/anu. 12189

Craig, R. S., Gardner, T. R., and Carnevali, O. (2017). “Growout and broodstock nutrition," in Marine Ornamental Species Aquaculture, eds R. Calado, I. Olivotto, M. Planas, and G. J. Holt (West Sussex: Wiley Blackwell), 139-158.

Dzyuba, B., Van Look, K. J. W., Cliffe, A., Koldewey, H. J., and Holt, W. V. (2006). Effect of parental age and associated size on fecundity, growth and survival in the yellow seahorse Hippocampus kuda. J. Exp. Biol. 209, 3055-3061. doi: $10.1242 /$ jeb.02336

Estévez, A., McEvoy, L. A., Bell, J. G., and Sargent, J. R. (1999). Growth, survival, lipid composition and pigmentation of turbot (Scophthalmus maximus) larvae fed live-prey enriched in arachidonic and eicosapentaenoic acids. Aquaculture 180, 321-343. doi: 10.1016/S0044-8486(99)00209-4

Faleiro, F., Almeida, A. J., Ré, P., and Narciso, L. (2016). Size does matter: an assessment of reproductive potential in seahorses. Anim. Reprod. Sci. 170, 61-67. doi: 10.1016/j.anireprosci.2016.04.003
Faleiro, F., and Narciso, L. (2010). Lipid dynamics during early development of Hippocampus guttulatus seahorses: searching for clues on fatty acid requirements. Aquaculture 37, 56-64. doi: 10.1016/j.aquaculture.2010.07.005

Faleiro, F., Narciso, L., and Vicente, L. (2008). Seahorse behaviour and aquaculture: How to improve Hippocampus guttulatus husbandry and reproduction? Aquaculture 28, 33-40. doi: 10.1016/j.aquaculture.2008.05.038

Fernández-Palacios, H., Izquierdo, M. S., Robaina, L., Valencia, A., Salhi, M., and Vergara, J. M. (1995). Effect of n - 3 HUFA level in broodstock diets on egg quality of gilthead sea bream (Sparus aurata L.). Aquaculture 132, 325-337. doi: 10.1016/0044-8486(94)00345-O

Fernández-Palacios, H., Norberg, B. G., Izquierdo, M., and Hamre, K. (2011). "Effects of broodstock diets on eggs and larvae," in Larval Fish Nutrition, ed. J. Holt (London: Wiley-Blackwell), 153-181. doi: 10.1002/97804709598 62.ch5

Foster, S. J., and Vincent, A. C. J. (2004). Life history and ecology of seahorses: implications for conservation and management. J. Fish Biol. 65, 1-61. doi: 10.1111/j.1095-8649.2004.00429.x

Giraudoux, P., Antonietti, J. P., Beale, C., Pleydell, D., and Treglia, M. (2018). Spatial Analysis and Data Mining for Field Ecologists v. 1.6.9. Available online at: https://cran.r-project.org/web/packages/pgirmess/index. html (accessed January 16, 2018).

Griffen, B. D. (2018). The timing of energy allocation to reproduction in an important group of marine consumers. PLoS One 13:e0199043. doi: 10.1371/ journal.pone.0199043

Gu, Z., Eils, R., and Schlesner, M. (2016). Complex Heatmaps Reveal Patterns and Correlations in Multidimensional Genomic Data. Bioinformatics. Available online at: http://bioconductor.org/packages/release/bioc/html/ ComplexHeatmap.html (accessed May 11, 2020).

Herbes, S. E., and Allen, C. P. (1983). Lipid quantification of freshwater invertebrates: method modification for microquantitation. Can. J. Fish. Aquat. Sci. 40, 1315-1317. doi: 10.1139/f83-150

Husson, F., Josse, J., Le, S., and Mazet, J. (2020). FactoMineR: Multivariate Exploratory Data Analysis and Data Mining. Available online at: https:/CRAN. R-project.org/package=FactoMineR (accessed March 20, 2020).

Izquierdo, M. S., Fernández-Palacios, H., and Tacon, A. G. J. (2001). Effect of broodstock nutrition on reproductive performance of fish. Aquaculture 197, 25-42. doi: 10.1016/S0044-8486(01)00581-6

Kassambara, A. (2020a). ggpubr: 'ggplot2' Based Publication Ready Plots. Available online at: https://CRAN.R-project.org/package=clinfun (accessed February 23, 2020).

Kassambara, A. (2020b). factoextra: Extract and Visualize the Results of Multivariate Data Analyses. Available online at: https://CRAN.R-project.org/package= factoextra (accessed February 23, 2020).

Kjørsvik, E., Mangorjensen, A., and Holmefjord, I. (1990). Egg quality in fishes. Adv. Mar. Biol. 26, 71-113. doi: 10.1016/S0065-2881(08)60199-6

Kuhn, M., Jackson, S., and Cimentada, J. (2020). Correlations in R. Available online at: https://CRAN.R-project.org/package=corrr (accessed March 27, 2020).

Kumaravel, K., Ravichandran, S., Balasubramanian, T., and Sonneschein, L. (2012). Seahorses - a source of traditional medicine. Nat. Prod. Res. 26, 2330-2334. doi: 10.1080/14786419.2012.662650

Lepage, G., and Roy, C. C. (1986). Direct transesterification of all classes of lipids in a one-step reaction. J. Lipid Res. 27, 114-120.

Lin, Q., Gao, Y. L., Sheng, J. Q., Chen, Q. X., Zhang, B., and Lu, J. Y. (2007). The effect of food and the sum of effective temperature on the embryonic development of the seahorse, Hippocampus kuda Bleeker. Aquaculture 262, 481-492. doi: 10.1016/j.aquaculture.2006.11.011

Lin, Q., Li, G., Qin, G., Lin, J., Huang, L., Sun, H., et al. (2012). The dynamics of reproductive rate, offspring survivorship and growth in the lined seahorse, Hippocampus erectus Perry, 1810. Biol. Open 1, 391-396. doi: 10.1242/bio. 2012398

Lin, Q., Lin, J., Lu, J., and Li, B. (2008a). Biochemical composition of six seahorse species, Hippocampus sp., from the Chinese, Coast. J. World Aquac. Soc. 29, 225-234. doi: 10.1111/j.1749-7345.2008.00159.x

Lin, Q., Lin, J., and Zhang, D. (2008b). Breeding and juvenile culture of the lined seahorse, Hippocampus erectus Perry, 1810. Aquaculture 277, 287-292. doi: 10.1016/j.aquaculture.2008.02.030

Lin, Q., Lu, J., Gao, Y., Shen, L., Cai, J., and Luo, J. (2006). The effect of temperature on gonad, embryonic development and survival rate of juvenile 
seahorses, Hippocampus kuda Bleeker. Aquaculture 254, 701-713. doi: 10.1016/ j.aquaculture.2005.11.005

Manning, C. G., Foster, S. J., and Vincent, A. C. J. (2019). A review of the diets and feeding behaviours of a family of biologically diverse marine fishes (Family Syngnathidae). Rev. Fish Biol. Fish. 29, 197-221. doi: 10.1007/s11160-01909549-z

Martin-Smith, K. M., Samoilys, M. A., Meeuwig, J. J., and Vincent, A. C. J. (2004). Collaborative development of management options for an artisanal fishery for seahorses in central Philippines. Ocean Coast. Manag. 47, 165-193. doi: 10.1016/j.ocecoaman.2004.02.002

McBride, R. S., Somarakis, S., Fitzhugh, G. R., Albert, A., Yaragina, N. A., Wuenschel, M. J., et al. (2015). Energy acquisition and allocation to egg production in relation to fish reproductive strategies. Fish Fish. 16, 23-57. doi: $10.1111 /$ faf. 12043

Migaud, H., Bell, G., Cabrita, E., McAndrew, B., Davie, A., Bobe, J., et al. (2013). Gamete quality and broodstock management in temperate fish. Rev. Aquac. 5(Suppl. 1), S194-S223. doi: 10.1111/raq.12025

Murugan, A., Dhanya, S., Sreepada, R. A., Rajagopal, S., and Balasubramanian, T. (2009). Breeding and mass scale rearing of three spotted seahorse, Hippocampus trimaculatus Leach under captive conditions. Aquaculture 290, 87-96. doi: 10. 1016/j.aquaculture.2009.01.033

Olivotto, I., Avella, M., Sampaolesi, G., Piccinetti, C. C., Ruiz, P., and Carnevali, O. (2008). Breeding and rearing the longsnout seahorse Hippocampus reidi: rearing and feeding studies. Aquaculture 283, 92-96.

Olivotto, I., Di Stefano, M., Rosetti, S., Cossignani, L., Pugnaloni, A., Giantomassi, F., et al. (2011a). Live prey enrichment, with particular emphasis on HUFAs, as limiting factor in false percula clownfish (Amphiprion ocellaris, Pomacentridae) larval development and metamorphosis: molecular and biochemical implications. Comp. Biochem. Physiol. A Mol. Integr. Physiol. 159, 207-218. doi: 10.1016/j.cbpa.2011.02.004

Olivotto, I., Planas, M., Simões, N., Holt, G. J., Avella, M. A., and Calado, R. (2011b). Advances in breeding and rearing marine ornamentals. J. World Aquac. Soc. 42, 135-166. doi: 10.1111/j.1749-7345.2011.00453.x

Otero-Ferrer, F., Izquierdo, M., Fazeli, A., Band, F., and Holt, W. V. (2016). Embryonic developmental plasticity in the long-snouted seahorse (Hippocampus reidi, Ginsburg 1933) in relation to parental preconception diet. Reprod. Fertil. Dev. 28, 1020-1028. doi: 10.1071/rd14169

Otero-Ferrer, F., Lättekivi, F., Ord, J., Reimann, E., Kõks, S., Izquierdo, M., et al. (2020). Time-critical influences of gestational diet in a seahorse model of male pregnancy. J. Exp. Biol. 2020:jeb210302. doi: 10.1242/jeb.210302

Otero-Ferrer, F., Molina, L., Socorro, J., Fernández-Palacios, H., and Izquierdo, M. (2012). Effect of different live prey on spawning quality of short-snouted seahorse, Hippocampus hippocampus (Linnaeus, 1758). J. World Aquac. Soc. 43, 174-186. doi: 10.1111/j.1749-7345.2012.00550.x

Paczolt, K. A., and Jones, A. G. (2010). Post-copulatory sexual selection and sexual conflict in the evolution of male pregnancy. Nature 464, 401-405. doi: 10.1038/ nature08861

Palma, J., Andrade, J. P., and Bureau, D. P. (2012). Growth, reproductive performances, and brood quality of long snout seahorse, Hippocampus guttulatus, fed enriched shrimp diets. J. World Aquac. Soc. 43, 802-813. doi: 10.1111/j.1749-7345.2012.00611.x

Palma, J., Andrade, J. P., and Bureau, D. P. (2017). The impact of dietary supplementation with astaxanthin on egg quality and growth of long snout seahorse (Hippocampus guttulatus) juveniles. Aquac. Nutr. 23, 304-312. doi: 10.1111/anu.12394

Palma, J., Stockdale, J., Correia, M., and Andrade, J. P. (2008). Growth and survival of adult long snout seahorse (Hippocampus guttulatus) using frozen diets. Aquaculture 278, 55-59. doi: 10.1016/j.aquaculture.2008.03.019

Pavlov, D., Kjørsvik, E., Refsti, T., and Anderson, O. (2004). "Brood stock and egg production," in Culture of Cold-Water Marine Fish, eds E. Moksness, E. Kjorsvik, and Y. Olsen (Oxford: Blackwell), 129-203.

Pedersen, T. L. (2020). ggraph: An Implementation of Grammar of Graphics for Graphs and Networks. Available online at: https://CRAN.R-project.org/ package $=$ ggraph (accessed March 26, 2020).

Planas, M., Blanco, A., Chamorro, A., Valladares, S., and Pintado, J. (2012). Temperature-induced changes of growth and survival in the early development of the seahorse Hippocampus guttulatus. J. Exp. Mar. Biol. Ecol. 438, 154-162. doi: 10.1016/j.jembe.2012.10.003
Planas, M., Burhans, R., and Simões, N. (2017a). "Seahorses and pipefish," in Marine Ornamental Species Aquaculture, eds R. Calado, I. Olivotto, M. Planas, and G. J. Holt (West Sussex: Wiley Blackwell), 299-326.

Planas, M., Silva, C., Quintas, P., Chamorro, A., and Piñero, S. (2017b). Ongrowing and enhancement of n-3 HUFA profile in adult Artemia: short- vs long-time enrichment. J. Appl. Phycol. 29, 1409-1420. doi: 10.1007/s10811-016-1016-z

Planas, M., and Chamorro, A. (2019). "Inheritance of stable isotopes in seahorses (Hippocampus reidi): effect of parental diet preceding breeding season," in Proceedings of the 43rd Annual Larval Fish Conference, Palma. doi: 10.13140/ RG.2.2.16922.08648

Planas, M., Chamorro, A., Paltrinieri, A., Campos, S., Jiménez, A., Nedelec, K., et al. (2020). Effect of diet on breeders and inheritance in syngnathids: application of isotopic experimentally derived data to field studies. Mar. Ecol. Prog. Ser. doi: 10.3354/meps13315

Planas, M., Chamorro, A., Quintas, P., and Vilar, A. (2008). Establishment and maintenance of threatened long-snouted seahorse, Hippocampus guttulatus, broodstock in captivity. Aquaculture 283, 19-28. doi: 10.1016/j.aquaculture. 2008.06.023

Planas, M., Quintas, P., and Chamorro, A. (2013). Maturation of Hippocampus guttulatus and Hippocampus hippocampus females by manipulation of temperature and photoperiod regimes. Aquaculture 388-391, 147-152. doi: 10. 1016/j.aquaculture.2013.01.030

Planas, M., Quintas, P., Chamorro, A., and Silva, C. (2010). Female maturation, egg characteristics and fatty acids profile in the seahorse Hippocampus guttulatus. Anim. Reprod. Sci. 122, 66-73. doi: 10.1016/j.anireprosci.2010.07.008

Planas, M., Quintas, P., and Chamorro, A. (2009a). "Growth of adult seahorses Hippocampus guttulatus fed exclusively on enriched adult Artemia (Project Hippocampus)," in Proceedings of the Book of Abstracts World Aquaculture Society World Aquaculture 2009, Veracruz, 669.

Planas, M., Quintas, P., and Silva, C. (2009b). "Snout abnormalities in young seahorses (Hippocampus guttulatus) (Project Hippocampus)," in Proceedings of the Book of Abstracts World Aquaculture Society Meeting, World Aquaculture 2009, Veracruz, 668.

Poortenaar, C. W., Woods, C. M. C., James, P. J., Giambartolomei, F. M., and Lokman, P. M. (2004). Reproductive biology of female big-bellied seahorses. J. Fish Biol. 64, 717-725. doi: 10.1111/j.1095-8649.2004.00341.x

Post, D. M. (2002). Using stable isotopes to estimate trophic position: models, methods, and assumptions. Ecology 83, 703-718.

R Core Team (2014). R: A Language and Environment for Statistical Computing. Vienna: R Foundation for Statistical Computing.

Rainuzzo, J. R. (1993). "Fatty acid and lipid composition of fish eggs and larvae," in Fish Farming Techonology, eds H. Reinertsen, L. A. Dahle, J. Jørgensen, and K. Tvinnereim (Rotterdam: Balkema), 43-48.

Rainuzzo, J. R., Reitan, K. I., and Olsen, Y. (1997). The significance of lipids at early stages of marine fish: a review. Aquaculture 155, 103-115. doi: 10.1016/S00448486(97)00121-X

Randazzo, B., Rolla, L., Ofelio, C., Planas, M., Gioacchini, G., Vargas Abúndez, J. A., et al. (2018). The influence of diet on the early development of two seahorse species ( $H$. guttulatus and $H$. reidi): traditional and innovative approaches. Aquaculture 490, 75-90. doi: 10.1016/j.aquaculture.2018.02.029

Saavedra, M., Batista, H., and Pousão-Ferreira, P. (2015). Dietary fatty acid enrichment during the spawning season increases egg viability and quality in Hippocampus hippocampus. Aquac. Nutr. 22, 343-351. doi: 10.1111/anu. 12252

Sagebakken, G., Ahnesjö, I., Mobley, K. B., Braga Gonçalves, I., and Kvarnemo, C. (2010). Brooding fathers, not siblings, take up nutrients from embryos. Proc. $R$. Soc. B 277, 971-977. doi: 10.1098/rspb.2009.1767

Sagebakken, G., Kvarnemo, C., and Ahnesjö, I. (2017). Nutritional state - a survival kit for brooding pipefish fathers. Biol. J. Linn. Soc 121, 312-318. doi: 10.1093/ biolinnean/blx002

Sargent, J., McEvoy, L., Estévez, A., Bell, G., Bell, M., Henderson, J., et al. (1999). Lipid nutrition of marine fish during early development: current status and future directions. Aquaculture 179, 217-229. doi: 10.1016/S0044-8486(99) 00191-X

Sargent, J. R., Henderson, R. J., and Tocher, D. R. (1989). “The lipids," in Fish Nutrition, ed. J. Halver (New York, NY: Academic Press), 153-218.

Sargent, J. R., Tocher, D. R., and Bell, J. G. (2002). "The lipids," in Fish Nutrition, eds J. E. Halver and R. W. Hardy (San Diego, CA: Academic Press), 181-257. 
Sarkar, D., Andrews, F., Wright, K., Klepeis, N., and Murrell, P. (2020). lattice: Trellis Graphics for $R$. Available online at: https://cran.r-project.org/web/ packages/lattice/index.html (accessed September 17, 2019).

Scobell, S. K., and MacKenzie, D. S. (2011). Reproductive endocrinology of Syngnathidae. J. Biol. Fish. 78, 1662-1680. doi: 10.1111/j.1095-8649.2011.02994. $\mathrm{x}$

Segade, A., Robaina, L., Novelli, B., Otero-Ferrer, F., and Molina Domínguez, L. (2016). Effect of the diet on lipid composition and liver histology of short snout seahorse Hippocampus hippocampus. Aquac. Nutr. 22, 1312-1319. doi: 10.1111/anu.12341

Segade, A., Robaina, L., Otero-Ferrer, F., García Romero, J., and Molina Domínguez, L. (2015). Effects of the diet on seahorse (Hippocampus hippocampus) growth, body colour and biochemical composition. Aquac. Res. 21, 807-813. doi: 10.1111/anu.12202

Siegel, S., and Castellan, N. J. (1988). Nonparametric Statistics for the Behavioral Sciences. New York, NY: McGraw-Hill.

Squadrito, F., Micali, A., Rinaldi, M., Irrera, N., Marini, H., Puzzolo, D., et al. (2017). Polydeoxyribonucleotide, an adenosine-A2 A receptor agonist, preserves blood testis barrier from cadmium-induced injury. Front. Pharmacol. 10:537. doi: 10.3389/fphar.2016.00537

Stölting, K. N., and Wilson, A. B. (2007). Male pregnancy in seahorses and pipefish: beyond the mammalian model. Bioessays 29, 884-896. doi: 10.1002/bies.20626

Tocher, D. R. (2003). Metabolism and functions of lipids and fatty acids in Teleost. Rev. Fish. Sci. 11, 107-184. doi: 10.1080/713610925

Tocher, D. R. (2010). Fatty acid requirements in ontogeny of marine and freshwater fish. Aquac. Res. 41, 717-732. doi: 10.1111/j.1365-2109.2008.02150.x

Valladares, S., and Planas, M. (2012). Non-lethal dorsal fin sampling for stable isotope analysis in seahorses. Aquat. Ecol. 46, 363-370. doi: 10.1007/s10452012-9407-y

Valladares, S., Soto, D. X., and Planas, M. (2016). Dietary composition of endangered seahorses determined by stable isotope analysis. Mar. Freshw. Res. 68, 831-839. doi: 10.1071/MF16013

Vargas-Abúndez, J. A., Simões, N., and Mascaró, M. (2018). Feeding the lined seahorse Hippocampus erectus with frozen amphipods. Aquaculture 491, 82-85. doi: 10.1016/j.aquaculture.2018.02.043

Venkatraman, E. S. (2018). Clinical Trial Design and Data Analysis Functions. Available online at: https://CRAN.R-project.org/package=clinfun (accessed February 4, 2020).

Viña, E., Parisi, V., Abbate, F., Cabo, R., Guerrera, M. C., Laurà, R., et al. (2014). Acid-sensing ion channel 2 (ASIC2) is selectively localized in the cilia of the non-sensory olfactory epithelium of adult zebrafish. Histochem. Cell Biol. 143, 59-68. doi: 10.1007/s00418-014-1264-4

Vincent, A. C. J. (1996). The International Trade in Seahorses. Cambridge: Traffic International.

Vincent, A. C. J., Foster, S. J., and Koldewey, H. J. (2011). Conservation and management of seahorses and other Syngnathidae. J. Fish Biol. 78, 1681-1724. doi: 10.1111/j.1095-8649.2011.03003.x

Volkoff, H., and London, S. (2018). "Nutrition and reproduction in fish," in Encyclopedia of Reproduction, ed. M. A. Skinner (Oxford: Elsevier), $743-748$.

Watanabe, T., Izquierdo, M. S., Takeuchi, T., Satoh, S., and Kitajima, C. (1989). Comparison between eicosapentaenoic and docosahexaenoic acids in terms of essential fatty acid efficacy in larval red seabream. Nippon Suisan Gakk. 55, 1635-1640. doi: 10.2331/suisan.55.1635

Wei, T., Simko, V., Levy, M., Xie, Y., Jin, Y., and Zemla, J. (2017). corrplot: Visualization of a Correlation Matrix. Available online at: https:/CRAN.Rproject.org/package $=$ corrplot (accessed March 6, 2020).

Wickham, H., Chang, W., Henry, L., Pedersen, T. L., Takahashi, K., Wilke, C., et al. (2020). ggplot2: Create Elegant Data Visualisations Using the Grammar of Graphics. Available online at: https://CRAN.R-project.org/package=ggplot2 (accessed September 17, 2019).

Wiegand, M. D. (1996). Composition, accumulation and utilization of yolk lipids in teleost fish. Rev. Fish Biol. Fish. 6, 259-286. doi: 10.1007/BF00122583

Williams, C. T., Klaassen, M., Barnes, B. M., Buck, C. L., Arnold, W., Giroud, S., et al. (2017). Seasonal reproductive tactics: annual timing and the capital-toincome breeder continuum. Philos. Trans. R Soc. B 372:20160250. doi: 10.1098/ rstb.2016.0250

Wilson, A. B., Vincent, A., Ahnesjö, I., and Meyer, A. (2001). Male pregnancy in seahorses and pipefishes (Family Syngnathidae): rapid diversification of paternal brood pouch morphology inferred from a molecular phylogeny. J. Heredity 92, 159-166. doi: 10.1093/jhered/92.2.159

Wittington, C. M., and Friesen, C. R. (2020). The evolution and physiology of male pregnancy in syngnathid fishes. Biol. Rev. doi: 10.1111/brv.12607

Wong, J. M., and Benzie, J. A. H. (2003). The effects of temperature, Artemia enrichment, stocking density and light on the growth of juvenile seahorses, Hippocampus whitei (Bleeker 1855), from Australia. Aquaculture 228, 107-121. doi: 10.1016/S0044-8486(03)00320-X

Woods, C. M. C. (2000). Improving initial survival in cultured seahorses, Hippocampus abdominalis Leeson, 1827 (Teleostei: Syngnathidae). Aquaculture 190, 377-388. doi: 10.1016/S0044-8486(00)00408-7

Woods, C. M. C. (2001). NIWA's seahorse project: past, present and future. Aquac. Update 27, 3-4.

Woods, C. M. C. (2009). Caprellid amphipods: an overlooked marine finfish aquaculture resource? Aquaculture 289, 199-211. doi: 10.1016/j.aquaculture. 2009.01.018

Woods, C. M. C., and Valentino, F. (2003). Frozen mysids as an alternative to live Artemia in culturing seahorses Hippocampus abdominalis. Aquac. Res. 34, 757-763. doi: 10.1046/j.1365-2109.2003.00882.x

Zhang, H., Chen, L., Zhang, B., and Lin, Q. (2019). Molecular identification of $\mathrm{GnIH}$ and its potential role in reproductive physiology and male pregnancy of the lined seahorse (Hippocampus erectus). Gen. Comp. Endocr. 279, 196-202. doi: 10.1016/j.ygcen.2019.04.018

Conflict of Interest: The authors declare that the research was conducted in the absence of any commercial or financial relationships that could be construed as a potential conflict of interest.

Copyright (c) 2020 Planas, Olivotto, González, Laurà and Zarantoniello. This is an open-access article distributed under the terms of the Creative Commons Attribution License (CC BY). The use, distribution or reproduction in other forums is permitted, provided the original author(s) and the copyright owner(s) are credited and that the original publication in this journal is cited, in accordance with accepted academic practice. No use, distribution or reproduction is permitted which does not comply with these terms. 